NBER WORKING PAPER SERIES

\title{
"WILL SOCIAL SECURITY BE THERE FOR YOU?": HOW AMERICANS PERCEIVE THEIR BENEFITS
}

\author{
Jeff Dominitz \\ Charles F. Manski \\ Jordan Heinz \\ Working Paper 9798 \\ http://www.nber.org/papers/w9798
NATIONAL BUREAU OF ECONOMIC RESEARCH 1050 Massachusetts Avenue
Cambridge, MA 02138
June 2003

This research was supported in part by National Institute on Aging Grant 2 P01 AG10179-04A1 and a grant from the Searle Fund. We are grateful to the University of Wisconsin Survey Center for enabling collection of the telephone survey data and to Jora Stixrud for assistance in performance of the face-to-face survey. We have benefited from the comments of participants in seminars at the Hebrew University of Jerusalem, Northwestern University, University College London, and the University of Pennsylvania; participants in the TMR Savings and Pensions Workshop held August 2001 in Evian, France; participants in the Conference on Survey Research on Household Expectations and Preferences held November 2001 in Ann Arbor, Michigan; and participants in the Institute for Research on Poverty 2002 Summer Workshop. An early version of this paper was distributed as "Social Security Expectations and Retirement Savings Decisions," National Bureau of Economic Research Working Paper w8718, January 2002. The views expressed herein are those of the authors and not necessarily those of the National Bureau of Economic Research.

C2003 by Jeff Dominitz, Charles F. Manski, and Jordan Heinz. All rights reserved. Short sections of text not to exceed two paragraphs, may be quoted without explicit permission provided that full credit including (C) notice, is given to the source. 
"Will Social Security Be There For You?: How Americans Perceive Their Benefits Jeff Dominitz, Charles F. Manski, and Jordan Heinz

NBER Working Paper No. 9798

June 2003

JEL No. H55, D84, E2

\begin{abstract}
$\underline{\text { ABSTRACT }}$
Americans may be uncertain of their future Social Security benefits for several reasons, including uncertainty about their future labor earnings, the formula now determining Social Security benefits, and the future structure of the Social Security system. To learn how Americans perceive their benefits, we have elicited Social Security expectations from respondents to the Survey of Economic Expectations. We have also performed a more intensive face-to-face survey on a small sample of respondents. We find clear and striking evidence of substantial uncertainty and heterogeneity of beliefs about the long-term existence of the Social Security system and about the level of benefits provided should the system survive.
\end{abstract}

Jeff Dominitz

H. John Heinz II School of Public Policy

and Management

Carnegie Mellon University

5000 Forbes Avenue

Pittsburgh, PA 15213

dominitz@andrew.cmu.edu

Jordan Heinz

University of Pennsylvania Law School

3400 Chestnut Street

Philadelphia, PA 19104

jheinz@law.upenn.edu
Charles F. Manski

Department of Economics and Institute for Policy Research

Northwestern University

2001 Sheridan Road

Evanston, IL 60208

and NBER

cfmanski@northwestern.edu 


\section{$\underline{1 . \text { Introduction }}$}

Americans may be uncertain of their future Social Security benefits for several reasons, including uncertainty about their future labor earnings, the formula now determining benefits, and the future structure of the Social Security system. Structural uncertainty is particularly pertinent today, as Congress and the President contemplate possibly radical revision of a Social Security system declared by President Bush's Commission to Strengthen Social Security to have "reached retirement age."1 Some proposed revisions, notably those calling for private investment of OASDI taxes, could increase uncertainty about future benefits. Other proposals, notably those calling for the government to create a "Social Security lockbox" of guaranteed benefits, could reduce uncertainty. The Social Security Administration (SSA) calls the public's attention to the possibility of future change in its document The Future of Social Security, which begins: "Will Social Security be there for you? Absolutely. The only real question is what kind of Social Security system we will have." 2

Although uncertainty about Social Security benefits should be widespread, there is reason to think that the degree and nature of this uncertainty varies systematically across the population. Under the existing formula with a benefit cap, older workers with histories of consistently high levels of earnings should face less uncertainty about their benefit levels than do those with histories of fluctuating earnings. ${ }^{3}$ Younger workers should face more labor earnings uncertainty

1 Richard W. Stevenson, New York Times, July 20, 2001.

${ }^{2}$ Social Security Administration Publication No. 05-10055, August 2000. http://www.ssa.gov/pubs/10055.html

${ }^{3}$ Expectations of benefits under the existing Social Security system may be influenced by the annual statements that workers now receive from the Social Security Administration. Beginning in October 1999, SSA has mailed workers of age 25 and older annual point estimates of their prospective benefits. Previously, a Personal Earnings and Benefit Estimate Statement had been available on request since 1988. See Section 5.3 for further discussion. 
than older workers, and also more uncertainty about the future structure of the system.

Research aiming to understand the impact of Social Security policy on labor supply, retirement savings, and other household decisions has been hampered by a dearth of empirical evidence on Social Security expectations. Respondents to the Retirement History Survey and to the Health and Retirement Study have provided point forecasts of their future benefits (see Bernheim, 1988; Gustman and Steinmeier, 1999, 2001). However, respondents' uncertainty about benefits has not been measured. Nor have attempts been made to learn the process by which persons form their expectations.

From summer 1999 through fall 2002, we elicited probabilistic expectations of Social Security retirement benefits from respondents to our national Survey of Economic Expectations (SEE), which began in 1993 and continued through 2002 (see Dominitz and Manski, 1997a, 1997b). Moreover, in the summer of 2001, we performed a more intensive face-to-face survey on a small sample of respondents. This paper presents the empirical findings.

To motivate interest in Social Security expectations, Section 2 observes how information on such expectations is necessary to understand retirement savings decisions. Section 3 describes the data on Social Security expectations that we have collected in the SEE and in the face-to-face survey. In Section 4, we present empirical findings that document striking uncertainty and heterogeneity of beliefs about the long-term existence of the Social Security system and about the level of benefits provided should the system survive. Younger Americans, particularly those under 45 , perceive a high probability of ineligibility for receipt of benefits at age 70. Conditional on receipt of benefits at 70, expectations for the level of benefits do not vary much by age, but substantial heterogeneity and uncertainty exist at all ages. Responses to openended survey questions about the sources of information and reasons for these beliefs provide a 
fuller picture of the formation of expectations about Social Security benefits. Section 5 draws conclusions.

\section{Social Security Expectations and Retirement Savings}

Optimal Savings Decisions in a Two-Period World

An idealized two-period model makes evident the role of Social Security expectations as a determinant of retirement savings. Suppose that a person lives for two periods, working in the first period and retiring in the second. In the first period, the person receives labor earnings and other income $\mathrm{Y}_{1}>0$, which he must allocate between consumption and retirement savings. Savings may be invested in part in a mutual fund, with uncertain real rate of return, and in part in a risk-free asset. Let $S^{m} \geq 0$ denote savings in the mutual fund and $S^{f} \geq 0$ denote risk-free savings. In the second period, the person consumes his Social Security retirement benefit $\mathrm{Y}_{2} \geq 0$ and realized savings $\left(1+r^{m}\right) S^{m}+\left(1+r^{f}\right) S^{f}$, where $r^{m}$ is the realized rate of return on the mutual fund and $\mathrm{r}^{\mathrm{f}}$ is the risk-free rate of return. Thus, consumption in the two periods must satisfy the budget constraints

$$
\begin{aligned}
& C_{1}=Y_{1}-S^{m}-S^{f} \\
& C_{2}=Y_{2}+\left(1+r^{m}\right) S^{m}+\left(1+r^{f}\right) S^{f} .
\end{aligned}
$$

The utility associated with consumption of the bundle $\left(C_{1}, C_{2}\right)$ is $U\left(C_{1}\right)+\beta U\left(C_{2}\right)$, where $\beta$ is the 
discount rate.

Suppose that, when facing the consumption-savings decision in the first period, the person knows his contemporaneous income $\mathrm{Y}_{1}$, but does not know either his future Social Security benefit $\mathrm{Y}_{2}$ or the return $\mathrm{r}^{\mathrm{m}}$ on the mutual fund. Suppose that he forms a subjective distribution $\mathrm{P}\left(\mathrm{Y}_{2}, \mathrm{r}^{\mathrm{m}}\right)$ and acts to maximize expected utility. Then, in the first period, the person chooses retirement savings to solve the problem

$$
\max _{S^{m}, S^{f}} U\left(Y_{1}-S^{m}-S^{f}\right)+\beta \int U\left(Y_{2}+\left(1+r^{m}\right) S^{m}+\left(1+r^{f}\right) S^{f}\right) d P\left(Y_{2}, r^{m}\right)
$$

Thus, a person's retirement savings decision depends on his first-period income $\mathrm{Y}_{1}$, his preferences $[U(),. \beta]$, and his expectations $\mathrm{P}\left(\mathrm{Y}_{2}, \mathrm{r}^{\mathrm{m}}\right)$ of Social Security benefits and mutual fund returns.

\section{Social Security Policy and Expectations}

In the context of this model, social security policy affects the retirement savings decision by influencing the person's expectations. Policy changes may affect the joint distribution $\mathrm{P}\left(\mathrm{Y}_{2}\right.$, $\left.\mathrm{r}^{\mathrm{m}}\right)$, but it is perhaps easiest to speculate on the changes to the marginal distribution $\mathrm{P}\left(\mathrm{Y}_{2}\right)$.

Consider creation of a "Social Security Lockbox" that guarantees future benefits to persons now working. Such a guarantee would presumably reduce the size of the left tail of $\mathrm{P}\left(\mathrm{Y}_{2}\right)$, as workers are relieved of the present-day concern with a catastrophic collapse of the Social Security system. However, the specific effect of the policy change on expectations would likely depend on the nature of the government guarantee. A government commitment to 
maintain present benefit levels may well have different effects on expectations than would a guarantee of some minimum benefit level.

Revision of the Social Security system to include private investment of a portion of OASDI taxes in a personal retirement account would change Social Security from a system of defined benefits to one with a defined-contribution component. When considering private pensions, it is commonly thought that such a change should increase the dispersion of benefit expectations and move their central tendency rightward. However, the effect on Social Security expectations may well depend on the specific form of the private-investment component and on other considerations. For example, Merton (1983) notes that a system combining defined benefits and defined contributions may yield a smaller total risk than a system of defined benefits alone or one of defined contributions alone. Feldstein and Liebman (2001) cite diversification as a leading argument offered by advocates of a mixed system.

The Need for Empirical Evidence on Expectations

A recent NBER volume on the risk aspects of investment-based Social Security reforms (Campbell and Feldstein, 2001) highlights the role of benefit expectations. Yet this volume contains no direct empirical evidence on these expectations. McHale (2001) attempts to infer the "political risks" of defined benefit systems from international evidence on changes in benefit rules. Campbell et al. (2001) connect defined-benefit uncertainty to labor income uncertainty through the Social Security benefit formula. Feldstein et al. (2001) suppose that defined benefits are known with certainty and use historical data on the performance of a diversified portfolio of securities to assess the financial risks of an investment-based system.

In the absence of empirical evidence, one can only speculate about how changes in Social 
Security policy would affect expectations, and thence retirement savings. A natural first step in assembling the necessary empirical evidence is to learn the expectations that Americans presently hold for Social Security benefits. This is the purpose of the surveys described in Section 3 .

\section{$\underline{\text { 3. Eliciting Expectations of Social Security Benefits }}$}

\subsection{The Survey of Economic Expectations}

The Survey of Economic Expectations, a periodic module in a continuous national telephone survey conducted by the University of Wisconsin Survey Center (UWSC), was begun in 1993 and continued through 2002. ${ }^{4}$ Dominitz and Manski (1997a, 1997b), Dominitz (1998, 2001), and Manski and Straub (2000) describe the survey design and report findings on expectations of income, job loss, and other outcomes one year into the future.

Beginning in 1999, the survey included a series of questions eliciting expectations of Social Security benefits from persons of ages $18-69 .^{5}$ This part of the survey begins with a brief description of the Social Security program and a request for the respondent to predict his eligibility for benefits when he is 70 years old, as follows: ${ }^{6}$

\footnotetext{
${ }^{4}$ UWSC discontinued the continuous survey in mid-2002. The SEE module of questions was then included as a module in the UWSC "national omnibus survey" in fall 2002. See http://www.wisc.edu/uwsc/national.htm

5 The national omnibus survey elicited the year of birth rather than age. For respondents to these interviews in fall 2002, we calculate age as 2002 minus year of birth.

6 These introductory instructions are intended to stimulate the respondent to consider the range of possible outcomes. It is possible that the instructions convey information that respondents use to form expectations.
} 
Politicians and the news media have been talking recently about the future of the Social Security retirement system, the federal program providing benefits to retired workers. The amount of benefits for which someone is eligible is currently determined by the person's retirement age and by earnings prior to retirement. There has been much discussion of changing the form of the Social Security system, so the future shape of the system is not certain.

With this in mind, I would like you to think about what kind of Social Security retirement benefits will be available when you are older. In particular, think ahead to when you are about to turn 70 years old and suppose that you are not working at that time.

What is the PERCENT CHANCE that you will be eligible to collect any Social Security retirement benefits at that time?

Respondents who report a positive probability are then asked a series of questions designed to elicit their subjective distribution of benefits, conditional on eligibility. This series follows the format of the income-expectations questions that have been asked in SEE since its inception (see Dominitz and Manski, 1997a). That is, respondents are first asked to report the lowest and highest possible levels of their future benefits. The responses are then used to set thresholds for up to six probabilistic questions about the level of benefits. ${ }^{7}$ The series has this form: ${ }^{8}$

Assessment of such effects based on systematic experimentation with alternative sets of instructions is a worthy subject for future research.

${ }^{7}$ For interviews conducted prior to April 2001, respondents were asked this series of probabilistic questions only if they gave valid responses to the questions eliciting lowest and highest possible values. Subsequently, we relaxed this requirement. However, to maintain comparability, we discard those probabilistic responses in the present analysis.

${ }^{8}$ Instructing respondents to ignore inflation in the introductory statement below is potentially important, because we are asking respondents to forecast as much as fifty-two years into the future. Similar instructions were given to respondents in our exploratory study of student expectations of the returns to schooling (Dominitz and Manski, 1996). 
Suppose you are eligible to collect Social Security benefits when you turn 70. Please think about how much money you would be eligible to collect EACH YEAR. When considering the dollar value, please ignore the effects of inflation or cost-of-living increases. That is, please respond as if a dollar today is worth the same as a dollar when you turn 70 .

What do you think is the LOWEST amount of Social Security benefits, per year, that you would be eligible to receive?

What do you think is the HIGHEST amount of Social Security benefits, per year, that you would be eligible to receive?

What is the percent chance (or chances out of 100) that you would be eligible to receive over $\$\{Y\}, 000$ of Social Security benefits per year, when you turn 70 ?

The responses to these questions may be used to estimate person-specific subjective probability distributions of benefit levels, conditional on eligibility for benefits, as will be explained in Section 4.3. In combination with the reported probability of eligibility, we may estimate unconditional subjective distributions of benefits. ${ }^{9}$

\subsection{Face-To-Face Interviews}

The more intensive face-to-face interviews were designed to complement the national telephone survey. A random sample of staff members at a midwestern university were asked

${ }^{9}$ For respondents who report a zero probability of eligibility, the unconditional distribution is necessarily degenerate at $\$ 0$. We do not elicit conditional probabilities of benefit levels from respondents who reported a zero chance of eligibility. These respondents are instead posed an open-ended question asking: "Why is that? (Why do you think there is no chance you will be eligible to collect any Social Security retirement benefits?)" We analyze responses to this question in Section 4.2. 
essentially the same questions as the SEE respondents, plus additional open-ended questions intended to explore how they went about forming their expectations. ${ }^{10}$ In particular, following the questions eliciting expectations of Social Security benefits, respondents were asked

Having answered these questions, please describe as best you can the considerations you had in mind when you were attempting to predict your Social Security retirement benefits.

The interview also includes a new segment eliciting perceptions of the current maximum annual Social Security benefit. Following an introductory statement, respondents were asked for their subjective probabilities of the maximum benefit exceeding various thresholds and then for a best point estimate. ${ }^{11}$ The segment closed with two open-ended questions. Here is the text:

Now think about Social Security benefits today. In particular, imagine a person who is now 70 years old. Suppose that this person retired from work at age 65 and began collecting benefits after working full time for 40 years. Suppose that, while working, this person had high enough income to be eligible for the maximum Social Security benefit that is currently paid.

\footnotetext{
${ }^{10}$ The one difference between the questions in SEE and in the face-to-face interviews concerned the thresholds for the probabilistic questions on benefit levels. The CATI software used in SEE enables application of a personspecific branching algorithm, but this was difficult to implement with the pencil-and-paper format of the face-toface interviews. Hence the same thresholds, ranging from $\$ 5,000$ to $\$ 25,000$, were posed to all respondents.

11 SEE elicits subjective probabilities only on the occurrence of future events, not on the value of objective quantities such as the current maximum Social Security benefit. However, the Bayesian idea that persons express uncertainty through subjective probabilities applies equally well to objective quantities and to future events.
} 
What is the PERCENT CHANCE that this person currently receives over $\$\{\mathrm{Y}\}, 000$ of Social Security benefits per year?

If you had to choose one number, what would be your best estimate of the benefits that this person receives per year?

Describe as best you can the current system that the government now uses to determine social security benefits. What are the main factors in calculating the size of the benefit? And so on.

When thinking about the previous question, please describe as best you can the sources from which you drew your information.

The interview concludes with a sequence of questions about expected income at age 70 from sources other than Social Security. Respondents report up to six probabilities corresponding to threshold values ranging from $\$ 10,000$ to $\$ 100,000$. An open-ended question concerning how these expectations were formed is asked as well. We do not analyze these data in this paper.

\section{SEE Findings}

\subsection{Sample Size, Response Rates, and Response Patterns}

The analysis in this paper is based on the 2850 SEE interviews completed from summer 1999, when the Social Security questions were introduced, through fall 2002. Of the 2850 
respondents, 2457 were age-eligible (i.e., under 70) for the Social Security questions. ${ }^{12}$ Of these, 2384 reported their chance of eligibility for benefits at age 70; thus the response rate to the eligibility question was 0.97 . Of these 2384 persons, 223 reported zero chance of receiving benefits. Hence 2161 persons were asked the questions eliciting lowest and highest possible benefits and the probabilities of benefits exceeding specified thresholds, conditional on eligibility. Of these 2161 persons, 1398 gave responses that could be used to estimate personspecific subjective distributions; thus the response rate to this sequence of questions was 0.65 . In all, we have unconditional subjective distributions of benefits for $1621(223+1398)$ persons. Our analysis focuses on these respondents, who constitute 0.66 of the age-eligible SEE sample members.

The overall response rate of 0.66 to the sequence of Social Security expectations questions is considerably lower than those that we have experienced asking SEE respondents to forecast simple binary events (typically 0.95 or more) and somewhat lower than our experience eliciting income expectations one-year-ahead (typically 0.80). About 80 percent (664 out of 836) of the non-response occurs when respondents do not report lowest/highest possible benefits. Another 14 percent did not respond to all of the probability questions asked, and the remaining 6 percent gave complete reports that could not be used to estimate person-specific subjective distributions.

With one-third of the sample having at least partially missing data, it is important to understand the cross-sectional pattern of non-response to the degree possible. Table 1 shows that respondents and non-respondents have similar mean age. However, non-respondents are more

\footnotetext{
${ }^{12}$ The first 2278 interviews were conducted as part of the UWSC continuous national telephone survey. The final 572 interviews were conducted as part of the UWSC omnibus survey in fall 2002.
} 
likely to be female, less likely to be non-Hispanic whites, less likely to be labor force participants, less likely to be married, and less likely to be high school or college graduates.

Figure 1 presents a kernel-smoothed estimate of the probability of non-response conditional on age. Here and elsewhere in the paper, we report bootstrap $90 \%$ confidence intervals based on 100 bootstrap samples. The estimated confidence intervals tend to be tight, because we have many observations and condition on only one regressor. Hence, we focus on the point estimates in our discussion. The figure shows a non-monotone pattern. The estimated nonresponse rate falls from a maximum of about 0.47 at age 21 to a minimum of about 0.27 at age 35. It then rises to a second maximum of about 0.40 at age 57 and falls again to about 0.28 at age 69 . We have no ready explanation for this age pattern.

\section{Comparison with HRS Response Rates}

The rate of non-response to the SEE Social Security questions, while troubling to some degree, compares favorably with the rate of non-response to Social Security expectations questions posed in the Health and Retirement Study (HRS). The HRS questions were asked only of the most "financially knowledgeable" member of the household, and then only if this person was not receiving benefits at the time of interview. Each such respondent was first asked if he or she expects to receive a benefit "at some time in the future." If the response is "yes," the respondent is asked the expected age of inception of benefits (i.e., retirement age) and the expected amount of benefits "in today's dollars" conditional on receipt at that age. A graphical depiction of the comparison of response rates is appended to this paper.

In the year 2000 survey, 4337 HRS respondents born after 1930 (i.e., under 70) were asked the yes/no expectations question, and 3745 said "yes." Of these, 3565 reported a valid 
retirement age, but only 2412 reported the expected level of benefits. Thus, information on the expected level of benefits was obtained from only $0.56(2412 / 4337)$ of the respondents queried about their Social Security expectations. ${ }^{13}$

Although differences in sampling frames and question sequences preclude precise comparison of the HRS and SEE response rates, we think that the difference stems largely from the HRS practice of eliciting expected benefit levels only from respondents who answer "yes" to the eligibility question. ${ }^{14}$ We have more to say about this below.

\subsection{Eligibility Expectations}

Among the 2384 SEE respondents who report a valid probability of eligibility for benefits at age 70 , the mean subjective probability of eligibility is 0.57 and the median is 0.60 . Figure 2 presents kernel-smoothed quantiles of eligibility probabilities conditional on age. The overall pattern is striking, with older respondents tending to report much higher probabilities of eligibility than do younger ones. For example, the estimated median probability of eligibility is 0.40 at age $30,0.50$ at age $40,0.70$ at age 50, 0.90 at age 60 , and 1.00 at age 65 . Thus, older Americans tend to be almost certain that, in one form or another, the Social Security system will

\footnotetext{
13 Other evidence on HRS response rates has been reported by Gustman and Steinmeier (1999, 2001), who analyze the Social Security expectations data collected in the 1992 interview. They report a response rate of 0.49 among those who (1) say "yes" to the eligibility question, regardless of age, (2) give permission to link Social Security Administration (SSA) data on their earnings histories, and (3) actually have their records linked (Gustman and Steinmeier, 2001). Approximately three-fourths of HRS respondents are said to satisfy the latter two criteria. Hence, about two-thirds of those who responded "yes" to the eligibility question and who had linkable records reported an expected level of benefits.

${ }^{14}$ SEE respondents are adults who live in households with telephones, while respondents to the HRS Social Security expectations questions are "financially-knowledgeable" individuals who are not receiving Social Security and live in households satisfying HRS age restrictions.
} 
survive at least ten more years. However, younger Americans have no such confidence in the continuation of the system until their retirement.

The first two columns of Table 2 present least absolute deviations (LAD) estimates of best linear predictors that describe the cross-sectional variation of eligibility probabilities with demographic and economic covariates of the respondents. The estimates in the first column of the table are based on the 2202 SEE respondents who report their eligibility probability and covariates, while those in the second column are based on the smaller sample of 1516 respondents who answer the entire sequence of expectations questions. Clearly age is the dominant predictor variable; in the two samples, the predicted chance of eligibility for benefits increases by 1.28 and 1.54 percentage points for every one-year increase in age. The other covariates have relatively little predictive power.

\section{Comparison with HRS Eligibility Expectations}

It is of interest to juxtapose the SEE and HRS eligibility questions and to compare the responses. The respective questions are:

SEE: Think ahead to when you are about to turn 70 years old and suppose that you are not working at that time. What is the PERCENT CHANCE that you will be eligible to collect any Social Security retirement benefits at that time?

HRS: Do you expect to receive Social Security benefits at some time in the future?

The questions and samples of respondents differ in several respects, but the main distinction is that the SEE question asks for a subjective probability while the HRS question asks 
for a yes/no response. Focusing on this distinction and abstracting from the others, responses to the two questions may be compared if we suppose that respondents asked the HRS question report best point predictions of benefit eligibility, obtained by minimizing the expected value of some symmetric loss function. As pointed out in Manski (1990), each respondent will answer "yes" if his or her subjective probability of eligibility exceeds a threshold that depends on the loss function and "no" if this probability is below the threshold. If the loss function is symmetric, the threshold probability is 0.5 . So a SEE respondent with subjective probability above 0.5 would report "yes" if asked the HRS question and one with subjective probability below 0.5 would report "no."

Figure 3 presents the actual fraction of HRS respondents of different ages who answer "yes" to the HRS eligibility question. The figure applies the reasoning of the paragraph above to estimate the fraction of SEE respondents who would have reported "yes" if they had been asked the HRS question. ${ }^{15}$ Comparison of the two plots shows that they are quite close to one another at all ages. The deviation narrows from about 0.06 at age 53 to basically 0 at age 61 and never reaches 0.02 at higher ages

This close correspondence suggests that HRS respondents who report "yes" may reasonably be interpreted as having subjective eligibility probabilities in the range $[0.5,1]$ and those who report "no" as having probabilities in the range $[0,0.5]$. This interpretation calls into question the HRS practice of not eliciting expected benefit levels from those who report "no." Such persons, particularly those with non-negligible subjective probabilities of eligibility, may

\footnotetext{
15 The estimates based on SEE data are kernel-smoothed. The HRS sample is large enough to eliminate the need for smoothing, so the actual year-by-year data are plotted. The HRS plot includes persons who currently receive benefits and assumes that such persons would have responded "yes" had they been asked the eligibility question. Among those who do not report "yes" are 741 respondents who report "no" and 80 who report "don't know."
} 
have well-formed beliefs regarding the benefits they would receive conditional on being eligible.

Who Perceives No Chance of Eligibility and Why?

Whereas interpretation of a "no" response to the HRS eligibility question is ambiguous, SEE respondents who report a zero probability of eligibility presumably really mean that they see no chance of receiving benefits. The frequency of such beliefs varies by age. Figure 4 presents a kernel-smoothed estimate of the conditional probability of a zero chance of eligibility for benefits at age 70 . The estimated proportion who perceive no chance of eligibility increases from 0.10 at age 20 to 0.17 at age 30 and then decreases to just 0.02 at age 65 .

SEE respondents who report a zero chance of eligibility may do so because they believe the system as a whole will fail to exist in any form and/or the system will exist but they will be ineligible to collect benefits at age 70 . The open-ended responses provided by the 223 respondents who reported a zero probability indicate that the potential failure of the Social Security system is the dominant explanation. About two-thirds of the responses (144 out of 223) describe a belief that the system will become insolvent and/or will cease to exist by the time the respondent turns 70 . Another 10 respondents assert that ineligibility will arise from prospective rule changes, such as an increase in the retirement age or means-testing of benefits. A total of 27 respondents do not comment on changes in the system but assert personal ineligibility based on current employment (e.g., government employee or minister), lack of an earnings history, or citizenship. A few respondents indicate a belief that they will not live until age 70 . The remaining responses are not easily classified in one of these categories. 


\subsection{Expectations of Benefit Levels}

\section{Central Tendency}

For each of the 1398 SEE respondents with complete expectations data and a positive subjective probability of eligibility for benefits, we fit a person-specific log-normal distribution to the elicited probabilities that benefits exceed different thresholds, conditional on eligibility. A succinct way to characterize these subjective distributions is through their medians, to express the central tendencies of respondents' expectations, and their interquartile ranges, to express respondents' uncertainty. In what follows, m denotes the median of a person's fitted log-normal distribution and q denotes its interquartile range. ${ }^{16}$

The cross-sectional median value of $m$ across the sample of 1398 respondents is $\$ 11,195$. According to SSA records, the average monthly benefit received in March 2001 by all beneficiaries age 65 or older was $\$ 817$, which equates to $\$ 9804$ annually. ${ }^{17}$ Among retired workers over age 65, the average benefit in March 2001 was $\$ 854$, or $\$ 10,248$ on an annual basis. These average figures for persons over 65 are not directly comparable to our crosssectional median of $\mathrm{m}$ for benefits at age 70 . However, the similarity of values does indicate that respondents have a reasonable general sense of the benefits they would receive, conditional on eligibility.

Figure 5 presents kernel-smoothed $0.25,0.50$, and 0.75 -quantile regressions of $\mathrm{m}$ on age.

\footnotetext{
${ }^{16}$ It has been traditional in the literature on consumption and savings to measure central tendency and uncertainty by the mean and variance of subjective log-income. We could transform our elicited Social Security benefit expectations into expectations of log-benefits, but we see no good reason to do so. Characterization of the central tendency and uncertainty by the subjective median and interquartile range of benefits seems to us much more natural and informative.
} 
Observe that the 0.25 -quantile rises from about $\$ 2,800$ to $\$ 5,000$ as age increases from 23 to 35 and then remains close to $\$ 5,000$ as age increases from 35 to 60 , before rising to $\$ 7,500$. The 0.50 -quantile dwells in the range $\$ 8,500$ - $\$ 10,000$ for persons of age $22-35$ and then in the range $\$ 10,000$ - $\$ 13,500$ for persons older than 35 . The 0.75 -quantile remains in the range $\$ 15,000$ $\$ 20,000$ for all persons older than 20 .

The main impression that we draw from Figure 5 is that the central tendencies of persons' expectations of benefit levels vary relatively little with age, but for a tightening of the crosssectional distribution of $\mathrm{m}$ above age 45 . In contrast, Figures 2 and 4 showed that expectations of eligibility rise dramatically with age. Juxtaposing these findings, we conclude that younger persons tend to be much less confident than older ones that Social Security will continue to exist when they retire but, conditional on continued existence of the system, they tend to expect that benefits will remain near current levels.

Figure 5 also makes plain that expectations of benefit levels vary substantially among persons of any given age. For example, the interquartile range of $\mathrm{m}$ is about $\$ 14,500(\$ 20,000$ $\$ 5500)$ at age 40 , about $\$ 11,000(\$ 17,000-\$ 6,000)$ at age 60 , and $\$ 7,500(\$ 15,000-\$ 7,500)$ above age 65. This heterogeneity in expectations presumably reflects a combination of real and perceptual factors. On the real side, the current system makes benefits vary with a person's own earnings and, in the case of survivor benefits, with the earnings of spouses; hence expectations should vary with personal and spousal past and expected labor earnings. On the perceptual side, persons may vary in their knowledge of how the Social Security system currently operates and in their expectations for the future structure of the system.

17 Available at http://www.ssa.gov/statistics/cos/pdf/2000/1b3.pdf. 
The third column of Table 2 presents LAD estimates of best linear predictors that describe the cross-sectional variation of $\mathrm{m}$ with various demographic and economic covariates of the respondents. Echoing Figure 5, we find that $\mathrm{m}$ varies little with age, increasing by only $\$ 45$ for every one-year increase in age. The variation with gender and schooling is more pronounced. Conditioning on other covariates, the predicted value of $\mathrm{m}$ is almost $\$ 4,000$ less for a women than for a man. According to SSA records, the average monthly benefit received in March 2001 by beneficiaries age 65 or older was $\$ 232$ higher for men than for women, which equates to a difference of $\$ 2,784$ annually. ${ }^{18}$ Conditioning on other covariates, individuals with schooling beyond high school are predicted to have subjective medians more than $\$ 3,000$ dollars higher than are individuals with no such schooling. This variation in expected benefits may reasonably arise from variation with schooling in life-cycle earnings streams. The predicted subjective median is about $\$ 4400$ higher for those who are widowed than for those who are married and more than $\$ 4500$ higher than for others, conditioning on other covariates. Of course, those who are widowed may obtain survivor benefits based in part on the earnings of the departed spouse.

\section{Uncertainty}

Across the sample of 1398 SEE respondents with complete expectations data and a positive probability of eligibility for benefits, the cross-sectional median of the subjective interquartile range $\mathrm{q}$ is $\$ 7,140$. Figure 6 presents kernel-smoothed $0.25,0.50$, and 0.75 -quantile regressions of $\mathrm{q}$ on age. The figure shows that subjective uncertainty about the magnitude of Social Security benefits is very substantial among young persons but decreases continuously with age. The 0.25 -quantile of $q$ dwells near $\$ 5,000$ up to age 40 and then falls to zero by age

\footnotetext{
${ }^{18}$ Available at http://www.ssa.gov/statistics/cos/pdf/2000/1b3.pdf
} 
57. Similarly, the 0.50 -quantile dwells near $\$ 10,000$ up to age 40 and falls to zero at age 67 . The 0.75 -quantile falls very sharply (roughly from $\$ 29,000$ to $\$ 20,000$ ) from age 20 to 25 , and continues to fall steadily thereafter, reaching a limit of about $\$ 3,100$ at age 69 .

That uncertainty about benefit levels should decrease with age makes much sense, because uncertainty about future labor earnings and about the future structure of Social Security should decrease as retirement nears. However, we take the main message of Figure 5 to be that even middle-aged persons who are nearing retirement tend to be rather uncertain of their future benefit levels, conditional on eligibility. For example, the median value of $q$ is $\$ 6,100$ among respondents of age 55, who are typically only ten years from retirement. ${ }^{19}$

The final column of Table 2 presents LAD estimates of best linear predictors that describe the cross-sectional variation of $\mathrm{q}$ with various demographic and economic covariates of the respondents. The strong variation with age echoes Figure 6; the predicted value of $\mathrm{q}$ decreases by $\$ 235$ dollars for every one-year decrease in age. The other covariates mainly have little predictive power. It appears that married individuals are more uncertain about their benefits, with a predicted interquartile range that is $\$ 2000$ wider than for those who are neither married nor widowed, conditioning on other covariates. The predicted range is $\$ 2400$ wider for those who are widowed.

\footnotetext{
${ }^{19}$ Analyzing the point expectations of future benefits elicited in the HRS, Gustman and Steinmeier (1999, 2001) conclude that respondents tend to misperceive the magnitude of the benefits they will receive. The pervasive uncertainty that SEE respondents reveal when questioned probabilistically makes us think that this conclusion is premature. We simply do not know how respondents who are uncertain of their future benefits choose point values when queried. Continuing the reasoning applied earlier to elicitation of eligibility, it may be that a person asked to provide a point prediction of his or her benefit level chooses a value that minimizes expected loss with respect to some loss function. If so, the reported value necessarily depends on the loss function used; the mean under square loss, the median under absolute loss, and so on.
} 


\section{Conditional Expectations of Benefits and Expectations of Eligibility}

We have focused thus far on expectations of benefits conditional on eligibility. We may also calculate unconditional expectations as the product of the conditional expectations and the eligibility probability. Before describing those expectations, we assess the relationship between the conditional expectations and the eligibility probability.

Figure 7 presents kernel-smoothed $0.25,0.50$, and 0.75 -quantile regressions of $\mathrm{m}$ on the subjective probability of eligibility among those with a non-zero eligibility probability. The results in Figure 7 are quite striking, with each quantile of m increasing nearly monotonically. The 0.25 -quantile increases from just $\$ 1,000$ conditional on a 1 percent chance of eligibility to $\$ 8,000$ conditional on a 100 percent chance of eligibility. The 0.50 -quantile increases from $\$ 3,300$ to $\$ 14,400$ over this range, and the 0.75 -quantile increases from under $\$ 10,000$ to $\$ 20,000$. Thus, those who perceive a smaller chance of receiving benefits also expect to receive fewer benefits should they receive any at all.

A related result arises from analysis of kernel-smoothed quantile regressions of $\mathrm{q}$ on the

eligibility probability, reported in Figure 8. We find that those who are more certain about eligibility for benefits (i.e., probabilities closer to 0 or 1) also tend to be more certain about the level of those benefits. For example, the 0.50 -quantile of $\mathrm{q}$ rises monotonically from about $\$ 4,000$ at a 1 percent chance of eligibility to about $\$ 12,600$ at a 62 percent chance and then falls steadily to about $\$ 3,100$ at a 100 percent chance. Once again, the 0.25 and 0.75 -quantiles vary similarly.

\section{Unconditional Expectations of Benefits}

Suppose that, instead of the sequence of questions posed in SEE, survey respondents 
were simply asked: "How much do you expect to receive in Social Security benefits at age 70?" Suppose further that these respondents try to provide a point prediction by minimizing expected absolute loss. Then, the best response would be the median of the unconditional subjective distribution of benefits at age 70 .

Figure 9 presents kernel-smoothed quantile regressions of the unconditional median of benefit expectations on age. The results here are very different from those presented in the Figure 5 for the conditional median. In particular, the 0.25 and 0.50 -quantiles equal $\$ 0$ until ages 57 and 45 respectively, at which point they increase sharply. The 0.75 -quantile increases tenfold from $\$ 1,500$ at age 25 to $\$ 15,000$ at age 69 . In contrast, the estimated quantiles of the conditional median in Figure 5 vary little with age.

This comparison highlights the extra information that is extracted by eliciting conditional expectations and the probability of the conditioning event, as opposed to direct elicitation of the unconditional expectations. By following the latter approach, one would have no idea that the increase of unconditional benefit expectations with age is driven mainly by systematic variation in perceptions of the probability of survival of the Social Security system as opposed to expectations of its generosity should it continue to exist.

\section{$\underline{\text { 5. Face-To-Face Interview Findings }}$}

In this section, we analyze survey responses obtained from 49 staff members at a midwestern university. The face-to-face interviews provide two important kinds of information not obtained from the SEE respondents. First, they provide respondents' expectations regarding 
the magnitude of current Social Security benefits. Second, they provide responses to open-ended questions through which we seek to learn about respondents' information sources and thought processes.

\subsection{Sample Size and Response Rates}

Originally, 123 individuals were randomly selected from the university's staff directory and were solicited by e-mail to participate in a study of perceptions of the Social Security retirement system and its future. The message stated that the face-to-face interview would take no longer than 20-30 minutes and that $\$ 15$ compensation would be paid. Forty percent of the persons solicited (49/123) agreed to be interviewed. The persons interviewed responded to essentially all of the questions posed. ${ }^{20}$

Although the face-to-face survey suffered none of the item response problems encountered in the SEE telephone interviews, it did run up against another problem that SEE largely avoids. As noted in Section 3.2, respondents to the face-to-face survey were asked to report probabilities that Social Security benefits exceed a series of predetermined thresholds ranging from $\$ 5,000$ to $\$ 25,000$, rather than the SEE series of person-specific thresholds generated by responses to the earlier questions on smallest and largest possible benefits. We found that some of the 49 respondents place high probability on benefits exceeding our top threshold of $\$ 25,000$. We were able to estimate the subjective distributions of these respondents

\footnotetext{
${ }^{20}$ Two respondents declined to report the smallest and largest possible Social Security benefits that they might receive at age 70. However, these and all other respondents did answer the subsequent sequence of questions asking for the probability that their benefits would exceed various predetermined thresholds.
} 
poorly, if at all.

\subsection{Expectations of Maximum Current Social Security Benefits}

\section{Central Tendency}

We measure expectations of current benefits by eliciting respondents' subjective distributions of the amount now paid to a 70-year-old retired worker who is "eligible for the maximum Social Security benefit" after retiring at age 65 . We were able to estimate subjective distributions for 43 of the 49 respondents. We were not able to estimate distributions for the remaining 6 respondents, each of whom reported a 100 percent chance that the current maximum exceeds $\$ 25,000$.

Among the 43 respondents with fitted subjective distributions of maximum benefits, the cross-sectional median value of the subjective median is about $\$ 18,500$. The cross-sectional median of respondents' point "best estimate" of the maximum benefit is $\$ 16,000$ for these 43 respondents, and $\$ 18,000$ for all 49 respondents. Based on information available from the SSA, we calculate the actual value of the maximum benefit to be $\$ 16,860 .^{21}$ Thus, the central tendencies of respondents' expectations tend to be reasonably in line with the facts.

In Section 4.3, we noted the absence of empirical evidence on how persons choose point estimates for quantities about which they are uncertain (see footnote 19). We can shed a bit of light on this matter by comparing the subjective medians and best estimates reported by the 43

\footnotetext{
21 A person who retired in 1996 at age 65 and was eligible for the maximum benefit received $\$ 1248$ per month at that time (see www.ssa.gov/OACT/COLA/exampleMax.html). Application of the yearly cost-of-living-adjustment (COLA) from 1996 onward shows that in 2001 this person, now 70 years old, received $\$ 1405$ per month, or $\$ 16,860$ per year.
} 
respondents for whom we have complete data. Figure 10 displays the 43 pairs of (subjective median, best estimate) values. The reader should focus on the cases in which the subjective median is greater than our lowest threshold of $\$ 5000$ and less than our top threshold of $\$ 25,000$. In this region, a forty-five degree line through the origin provides a reasonably good overall fit to the data, with residuals that rarely exceed $\$ 5000$.

\section{Uncertainty}

Figure 11 displays the subjective interquartile ranges of respondents' subjective distributions, along with their subjective medians. The striking conclusion is that respondents tend to be very uncertain about the current maximum benefit, with most values being above $\$ 5000$, and many being above $\$ 10,000$. There is no evident association between respondents' subjective medians and subjective interquartile ranges.

\section{Expectations of Own Future Benefits and Maximum Current Benefits}

Figures 12 and 13 compare respondents' expectations of maximum current benefits with their expectations of their own future benefits. Figure 12 plots respondents' subjective medians for these two quantities, while Figure 13 plots their subjective interquartile ranges.

Figure 12 shows a clear positive relationship between the two subjective medians. In most cases, the data lie somewhat below the 45-degree line, indicating that respondents expect their own benefit to be smaller than current benefits. This makes sense for two reasons. First, should the future formula remain the same as today's, some respondents may believe that their life-cycle earnings will not qualify them for the maximum benefits. Second, to the extent that respondents believe the future formula will differ from today's, the tenor of the recent public 
discussion of Social Security makes it reasonable to expect that benefits will fall rather than rise.

Figure 12 offers a glimpse of the relationship between "formula uncertainty" (i.e., uncertainty about the current amount paid to a retired worker with a specific earnings history) and the total uncertainty an individual perceives about benefits to be paid at age 70, conditional on eligibility. The latter uncertainty includes not only formula uncertainty, but also earnings uncertainty and uncertainty about the future structure of the system. The figure indicates a weak positive relationship between formula uncertainty and total uncertainty. However, we do not find that total uncertainty generally exceeds formula uncertainty. As often as not, the interquartile range of maximum current benefits exceeds that of own future benefits.

\subsection{Open-Ended Responses}

In response to open-ended questions, subjects described for us their understanding of the Social Security system, as well as the information on which their understanding is based. The dominant source of information reported by respondents is the annual statement that workers now receive from the SSA. Fully 43 of the 49 respondents indicated that they based their expectations on SSA mailings, with the majority clearly describing the annual report. Other than these documents, no strong pattern emerged. Several respondents indicated that they infer the level of benefits from observation of or conversations with relatives or acquaintances currently collecting benefits.

Our introduction to the module on future benefit expectations informed respondents that

current benefits are "determined by retirement age and by earnings prior to retirement." When later asked to describe the factors that currently determine benefits, more than half of the 
respondents indicated a link between earnings histories and benefits. However, the responses rarely suggested a full understanding of the formula. Some respondents expressed a belief that benefits are based on earnings at retirement or over the preceding few years, as is common in employer-provided defined-benefit pension plans. Six respondents expressed a belief that benefits are mean-tested, and one speculated that benefits would be means-tested in the future.

\section{Conclusion}

The empirical findings reported in Sections 4 and 5 add substantially to the rather limited empirical evidence that was previously available on Social Security expectations. The SEE findings on the variation of expectations with age are particularly interesting. We found that younger persons tend to be much less confident than older ones that Social Security will continue to exist when they retire. We estimate the median subjective probability of eligibility for benefits to be 0.40 at age $30,0.50$ at age $40,0.70$ at age $50,0.90$ at age 60 , and 1.00 at age 65 . Moreover, a sizeable fraction of Americans perceive no chance of eligibility, especially those under age 45 who foresee insolvency of Social Security in the next 25-50 years. We also found that, conditioning on continued existence of the system, younger persons and older ones both tend to expect that benefits will remain near current levels. Hence the prevalent concern among younger persons appears to be that the Social Security system will collapse entirely, not that benefits will be reduced to keep the system going.

Also notable is the extent of uncertainty about benefit levels. The SEE data show that even middle-aged persons who are nearing retirement tend to have large subjective interquartile 
ranges for their future benefit levels, conditional on eligibility. These persons face relatively little uncertainty about their future labor earnings or about the future structure of the Social Security system, so the main source of their uncertainty about benefits must be uncertainty about the formula determining current benefits. Our face-to-face interviews provide direct empirical evidence that formula uncertainty is substantial.

The expectations data analyzed here provide some of the empirical evidence necessary to forecast how proposed changes in Social Security policy would affect retirement savings and labor supply decisions. We would like to use these data to provide some sense of the impacts that may occur, but realistic forecasting of policy impacts requires other empirical evidence (as well as a less idealized decision model than the one presented in Section 2). For one thing, we need to know the expectations that persons hold for the returns to private savings. For another, we need to understand how changes in policy would affect the expectations that persons hold. And, of course, forecasting labor supply and savings decisions requires empirical evidence on preferences. 


\section{$\underline{\text { References }}$}

Bernheim, B. D. (1988). "Social Security Benefits: An Empirical Study of Expectations and Realizations," in R.R. Campbell and E. Lazear, eds., Issues in Contemporary Retirement, Stanford, CA: Hoover Institution.

Campbell, J. and M. Feldstein, eds. (2001), Risk Aspects of Investment-Based Social Security Reform, Chicago: University of Chicago Press.

Campbell, J., J. Cocco, F. Gomes, and P. Maenhout (2001). "Investing Retirement Wealth: A Life-Cycle Model," in J. Campbell and M. Feldstein, eds., Risk Aspects of Investment-Based Social Security Reform, Chicago: University of Chicago Press.

Dominitz, J. (1998), "Earnings Expectations, Revisions, and Realizations," Review of Economics and Statistics, 80, 374-388.

Dominitz, J. (2001). "Estimation of Income Expectations Models Using Expectations and Realizations Data,” Journal of Econometrics, 102, 165-195.

Dominitz, J. and C. Manski (1996). "Eliciting Student Expectations of the Returns to Schooling," Journal of Human Resources, 31, 1-26.

Dominitz, J. and C. Manski (1997a). "Using Expectations Data to Study Subjective Income Expectations," Journal of the American Statistical Association, 92, 855-867.

Dominitz, J. and C. Manski (1997b). "Perceptions of Economic Insecurity: Evidence from the Survey of Economic Expectations," Public Opinion Quarterly, 61, 261-287.

Feldstein, M., and J. Liebman (2001). "Social Security,” NBER Working Paper 8451.

Feldstein, M., E. Ranguelova, and A. Samwick (2001). "The Transition to Investment-Based Social Security When Portfolio Returns and Capital Profitability are Uncertain," in J. Campbell and M. Feldstein, eds., Risk Aspects of Investment-Based Social Security Reform, Chicago: University of Chicago Press.

Gustman, A. and T. Steinmeier (1999). "What People Don't Know About Their Pensions and Social Security: An Analysis Using Linked Data from the Health and Retirement Study," NBER Working Paper 7368.

Gustman, A. and T. Steinmeier (2001). "Imperfect Knowledge, Retirement, and Savings," NBER Working Paper 8406.

Manski, C. (1990). "The Use of Intentions Data to Predict Behavior: A Best-Case Analysis," Journal of the American Statistical Association, 85, 934-940. 
Manski, C. and J. Straub (2000), "Worker Perceptions of Job Insecurity in the Mid-1990s: Evidence from the Survey of Economic Expectations," Journal of Human Resources 35, 447479.

McHale, J. (2001). "The Risk of Social Security Benefit-Rule Changes: Some International Evidence," in J. Campbell and M. Feldstein, eds., Risk Aspects of Investment-Based Social Security Reform, Chicago: University of Chicago Press.

Merton, R. (1983). "On the Role of Social Security as a Means for Efficient Risk Sharing in an Economy Where Human Capital is Not Tradable," in Z. Bodie and J. Shove, eds., Financial Aspects of the United States Pension System, Chicago: University of Chicago Press. 


\begin{tabular}{|c|c|c|c|}
\hline \multicolumn{3}{|c|}{ Table 1. Descriptive Statistics: Survey of Economic Expectations 1999-2002 } \\
\hline Variable & $\begin{array}{c}\text { All Age Eligible } \\
\text { (2457 observations) }\end{array}$ & $\begin{array}{c}\text { Respondents } \\
\text { (1621 observations) }\end{array}$ & $\begin{array}{c}\text { Non-Respondents } \\
\text { (836 observations) }\end{array}$ \\
\cline { 2 - 4 } Age (years) & sample mean & sample mean & sample mean \\
Female & 42.18 & 42.39 & 41.79 \\
In Labor Force & 0.52 & 0.49 & 0.59 \\
High School Graduate & 0.80 & 0.81 & 0.78 \\
Bachelor's Degree or More & 0.92 & 0.94 & 0.89 \\
White, Non-Hispanic & 0.39 & 0.41 & 0.37 \\
African-American, Non-Hispanic & 0.81 & 0.83 & 0.77 \\
Married and Residing with Spouse & 0.07 & 0.07 & 0.08 \\
Widowed & 0.54 & 0.56 & 0.49 \\
\hline
\end{tabular}




\section{Table 2. Best Linear Predictors of Social Security Expectations: LAD Estimates}

\begin{tabular}{|c|c|c|c|c|}
\hline Predictor Variable & $\begin{array}{l}\text { Percent Chance of } \\
\text { Eligibility at Age } 70 \\
\text { (all respondents) }\end{array}$ & $\begin{array}{l}\text { Percent Chance of } \\
\text { Eligibility at Age } 70 \\
\text { (respondents with } \\
\text { complete data) }\end{array}$ & $\begin{array}{l}\text { Median m of Benefits } \\
(\$), \text { Conditional on } \\
\text { Eligibility }\end{array}$ & $\begin{array}{l}\text { IQR q of Benefits } \\
(\$), \text { Conditional on } \\
\text { Eligibility }\end{array}$ \\
\hline Age (years) & $\begin{array}{l}1.28 \\
(0.08)\end{array}$ & $\begin{array}{l}1.54 \\
(0.11)\end{array}$ & $\begin{array}{c}45.04 \\
(24.21)\end{array}$ & $\begin{array}{r}-235.78 \\
(62.89)\end{array}$ \\
\hline Female & $\begin{array}{l}-8.56 \\
(1.75)\end{array}$ & $\begin{array}{l}-7.69 \\
(2.49)\end{array}$ & $\begin{array}{l}-3923.10 \\
(570.82)\end{array}$ & $\begin{array}{c}521.65 \\
(1243.04)\end{array}$ \\
\hline Labor Force Participant & $\begin{array}{l}-4.24 \\
(2.37)\end{array}$ & $\begin{array}{l}-2.31 \\
(3.24)\end{array}$ & $\begin{array}{l}-626.53 \\
(805.31)\end{array}$ & $\begin{array}{c}779.39 \\
(1866.45)\end{array}$ \\
\hline $\begin{array}{c}\text { Some School After } \\
\text { High School }\end{array}$ & $\begin{array}{l}-0.44 \\
(2.41)\end{array}$ & $\begin{array}{c}1.54 \\
(3.76)\end{array}$ & $\begin{array}{l}3132.23 \\
(756.38)\end{array}$ & $\begin{array}{c}122.39 \\
(1404.48)\end{array}$ \\
\hline $\begin{array}{c}\text { Bachelor's Degree or } \\
\text { More }\end{array}$ & $\begin{array}{l}3.16 \\
(2.28)\end{array}$ & $\begin{array}{c}6.15 \\
(3.88)\end{array}$ & $\begin{array}{l}3185.62 \\
(733.14)\end{array}$ & $\begin{array}{c}1016.26 \\
(1165.84)\end{array}$ \\
\hline White, Non-Hispanic & $\begin{array}{c}1.68 \\
(3.80)\end{array}$ & $\begin{array}{c}7.69 \\
(6.28)\end{array}$ & $\begin{array}{c}1530.53 \\
(1198.52)\end{array}$ & $\begin{array}{c}594.79 \\
(1161.58)\end{array}$ \\
\hline $\begin{array}{l}\text { African American, } \\
\text { Non-Hispanic }\end{array}$ & $\begin{array}{c}0.36 \\
(5.79)\end{array}$ & $\begin{array}{c}4.62 \\
(7.50)\end{array}$ & $\begin{array}{c}608.53 \\
(1733.65)\end{array}$ & $\begin{array}{c}3226.54 \\
(2311.18)\end{array}$ \\
\hline $\begin{array}{l}\text { Married and Residing } \\
\text { with Spouse }\end{array}$ & $\begin{array}{l}-5.00 \\
(1.94)\end{array}$ & $\begin{array}{l}-3.08 \\
(2.55)\end{array}$ & $\begin{array}{l}135.11 \\
(640.38)\end{array}$ & $\begin{array}{c}2073.53 \\
(1013.31)\end{array}$ \\
\hline Widowed & $\begin{array}{c}4.76 \\
(2.97)\end{array}$ & $\begin{array}{c}6.15 \\
(3.92)\end{array}$ & $\begin{array}{c}4549.64 \\
(2182.76)\end{array}$ & $\begin{array}{c}2398.50 \\
(1784.90)\end{array}$ \\
\hline Intercept & $\begin{array}{l}15.52 \\
(6.53)\end{array}$ & $\begin{array}{l}-10.77 \\
(9.65)\end{array}$ & $\begin{array}{c}6693.26 \\
(1884.18)\end{array}$ & $\begin{array}{l}14730.96 \\
(4882.65)\end{array}$ \\
\hline Number of Observations & 2202 & 1516 & 1323 & 1323 \\
\hline
\end{tabular}

Bootstrap standard errors are reported in parentheses. Other than Age, all predictors are dichotomous. 
Figure 1. Nonresponse Probability for Social Security Expectations Questions, Conditional on Age

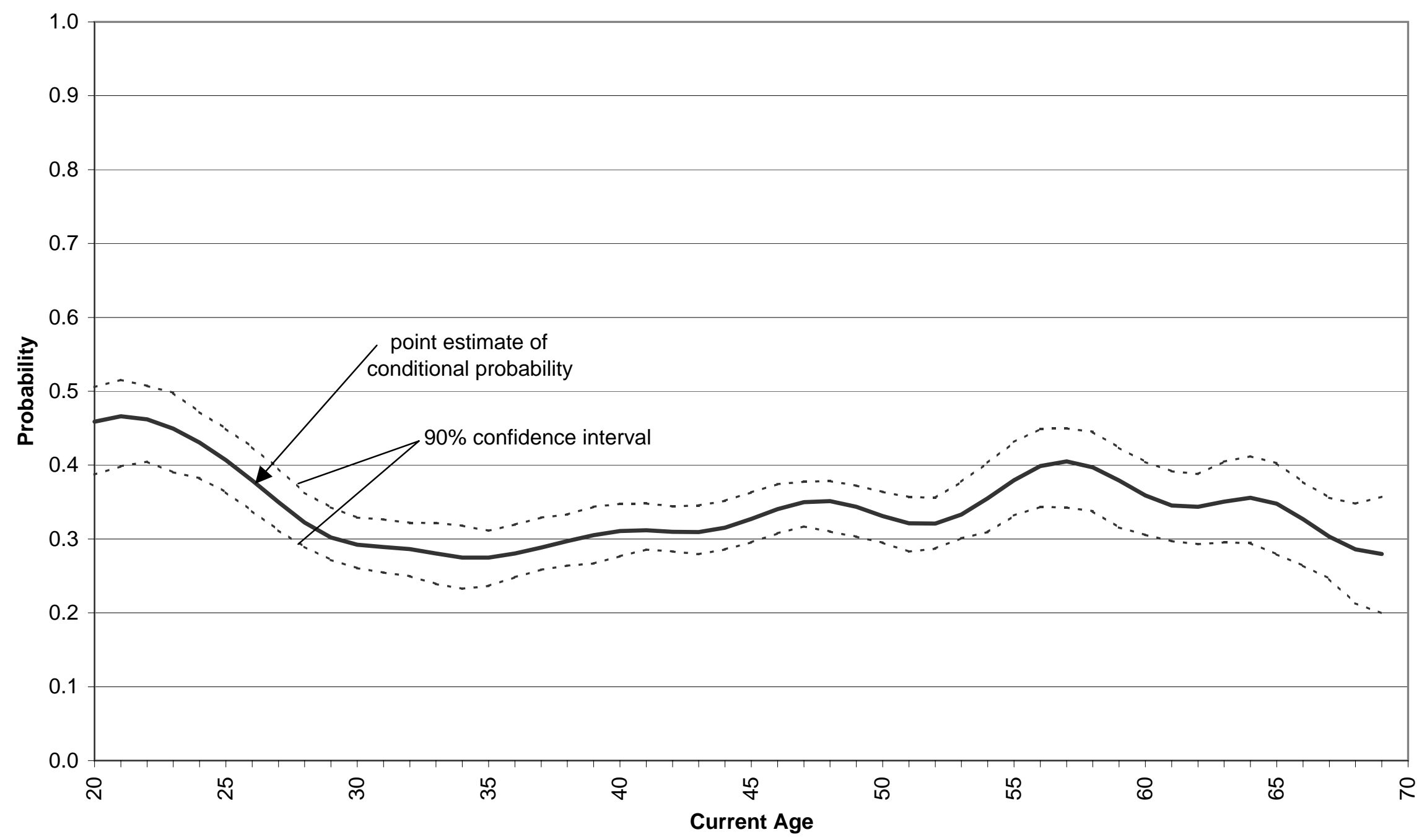

Conditional probabilities estimated using gaussian kernel with bandwidth of two years (2457 observations). Solid curve depicts point estimates. Dashed curves depict bootstrap $90 \%$ confidence intervals. 
Figure 2. Quantiles of Probability of Receiving Social Security Benefits at Age 70, Conditional on Current Age

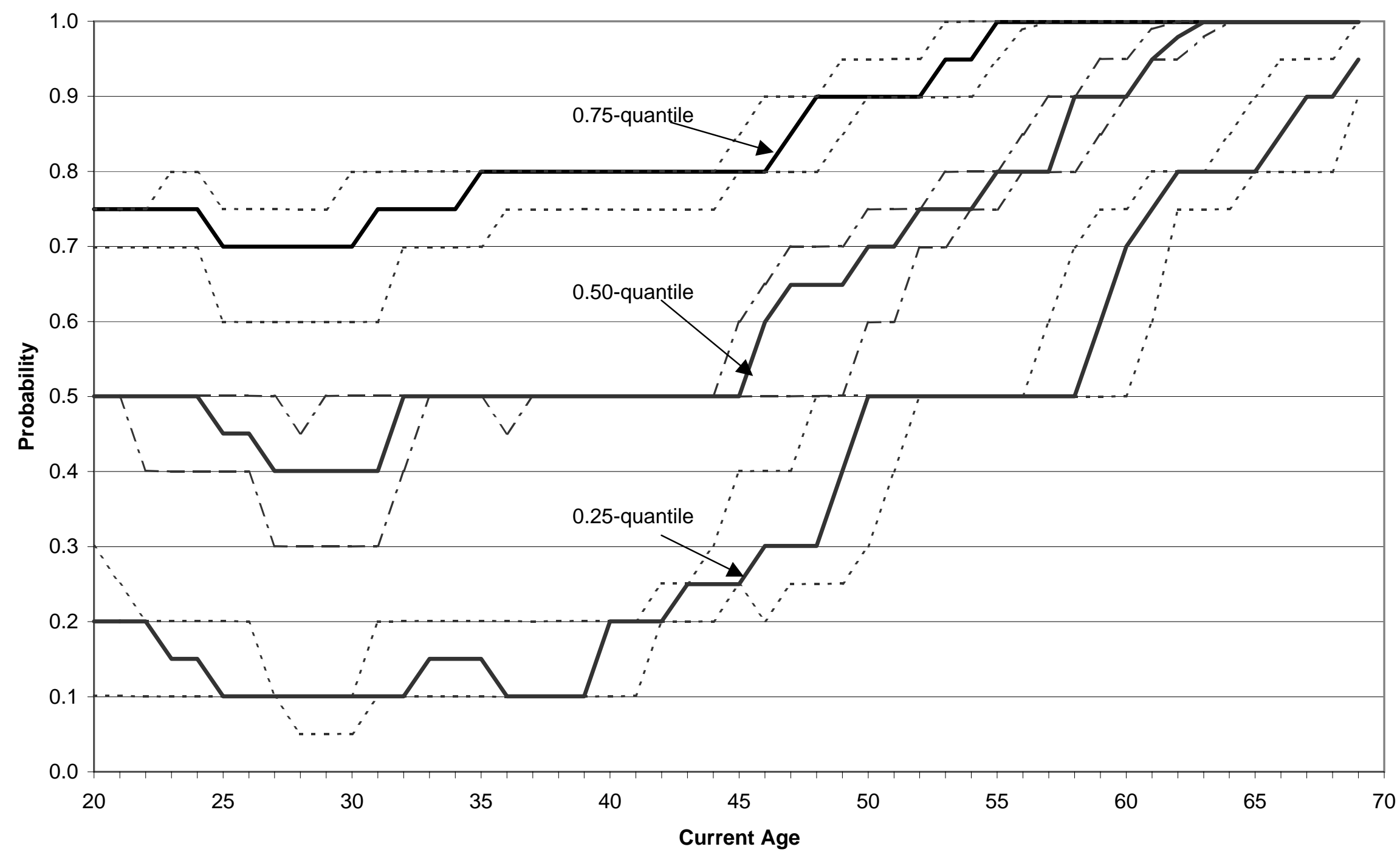

Conditional quantiles estimated using gaussian kernel with bandwidth of two years (2384 observations). Solid curves depict point estimates. Dashed curves depict bootstrap $90 \%$ confidence intervals. 
Figure 3. Probability of "Yes" Response to Dichotomous Social Security Eligibility Question: Health and Retirement Study (HRS) and Survey of Economic Expectations (SEE)

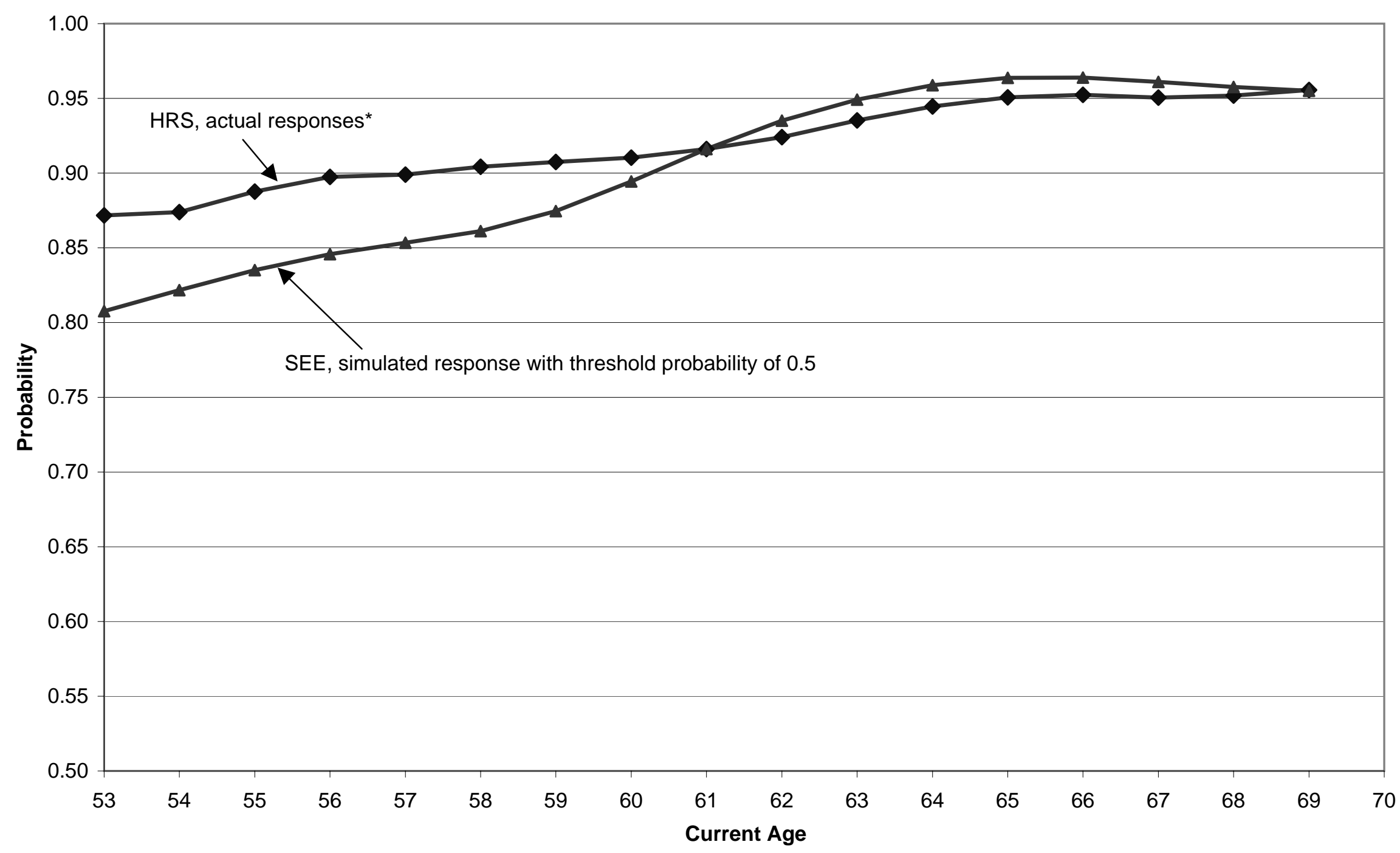

* HRS: "Financially-knowledgeable" respondents who report "yes," "no," or "don't know." If currently receives benefits, "yes" is imputed. SEE: Conditional probabilities estimated using gaussian kernel with bandwidth of 2 years. 
Figure 4. Probability of No Chance of Eligibility for Social Security, Conditional on Age

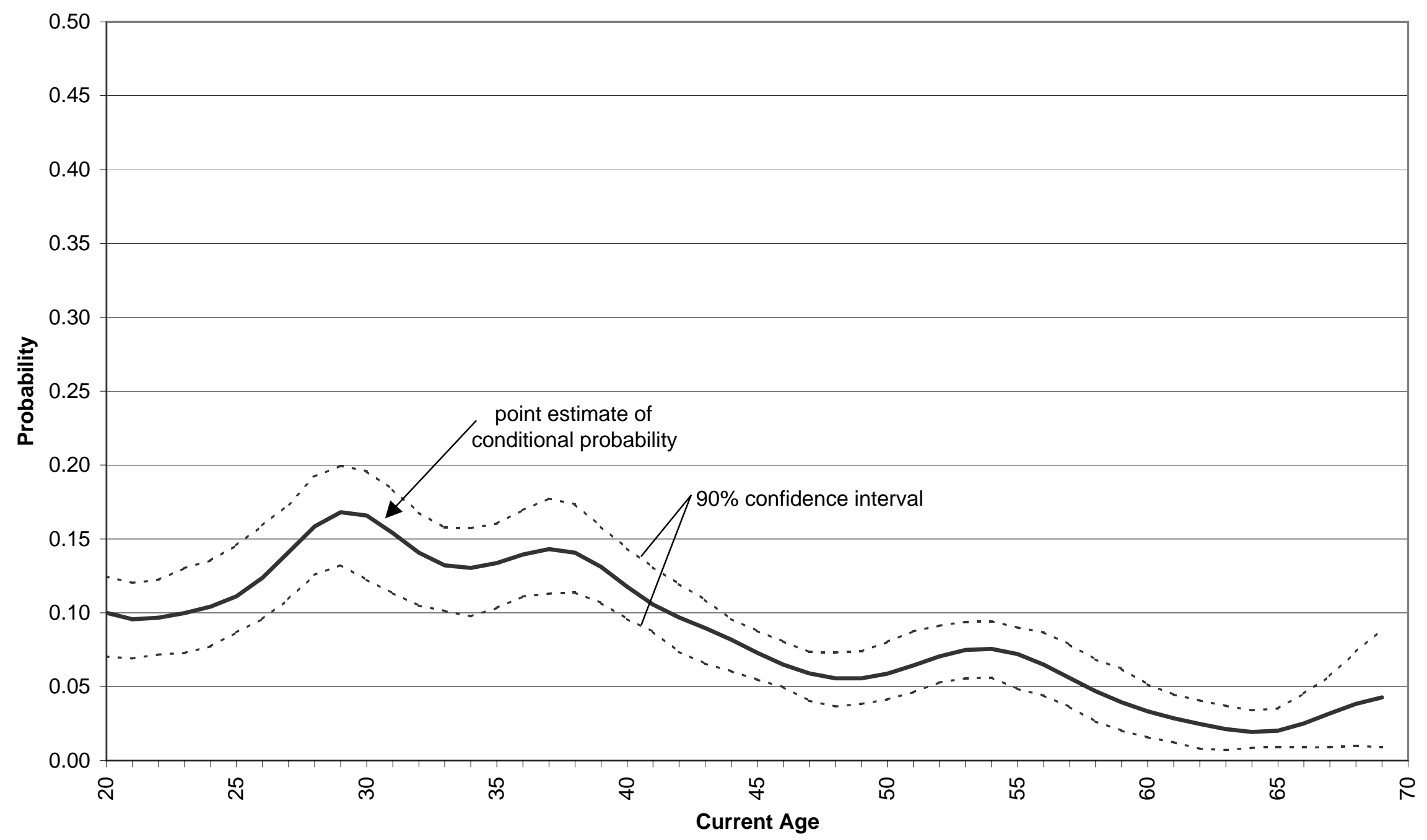

Conditional probabilities estimated using gaussian kernel with bandwidth of two years (2384 observations). Solid curve depicts point estimates. Dashed curves depict bootstrap $90 \%$ confidence intervals. 
Figure 5. Quantiles of Subjective Median of Benefits at Age 70, Conditional on Current Age

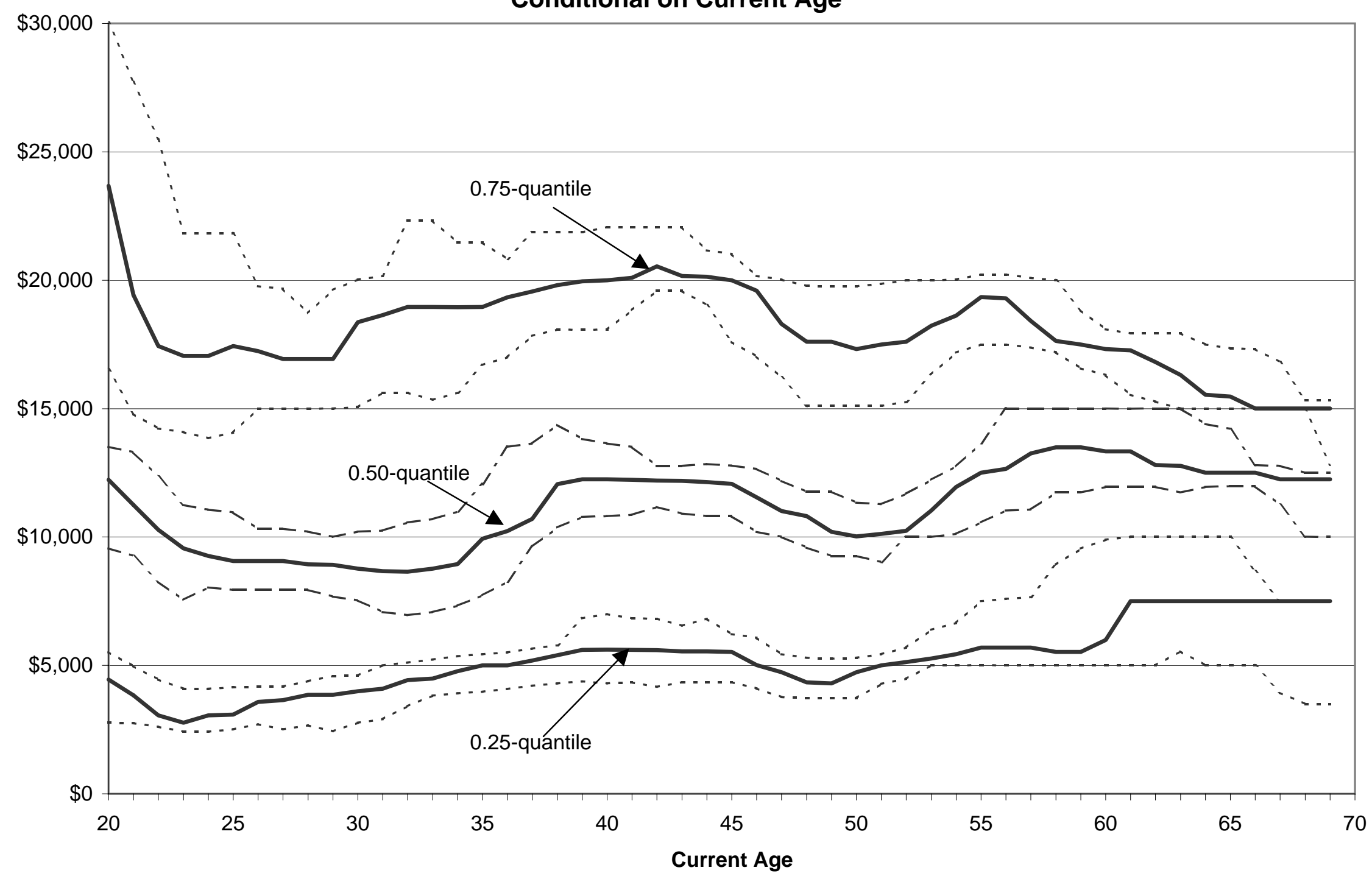

Conditional quantiles estimated using gaussian kernel with bandwidth of two years (1398 observations). Solid curves depict point estimates. Dashed curves depict bootstrap $90 \%$ confidence intervals. 
Figure 6. Quantiles of Subjective IQR of Benefits at Age 70,

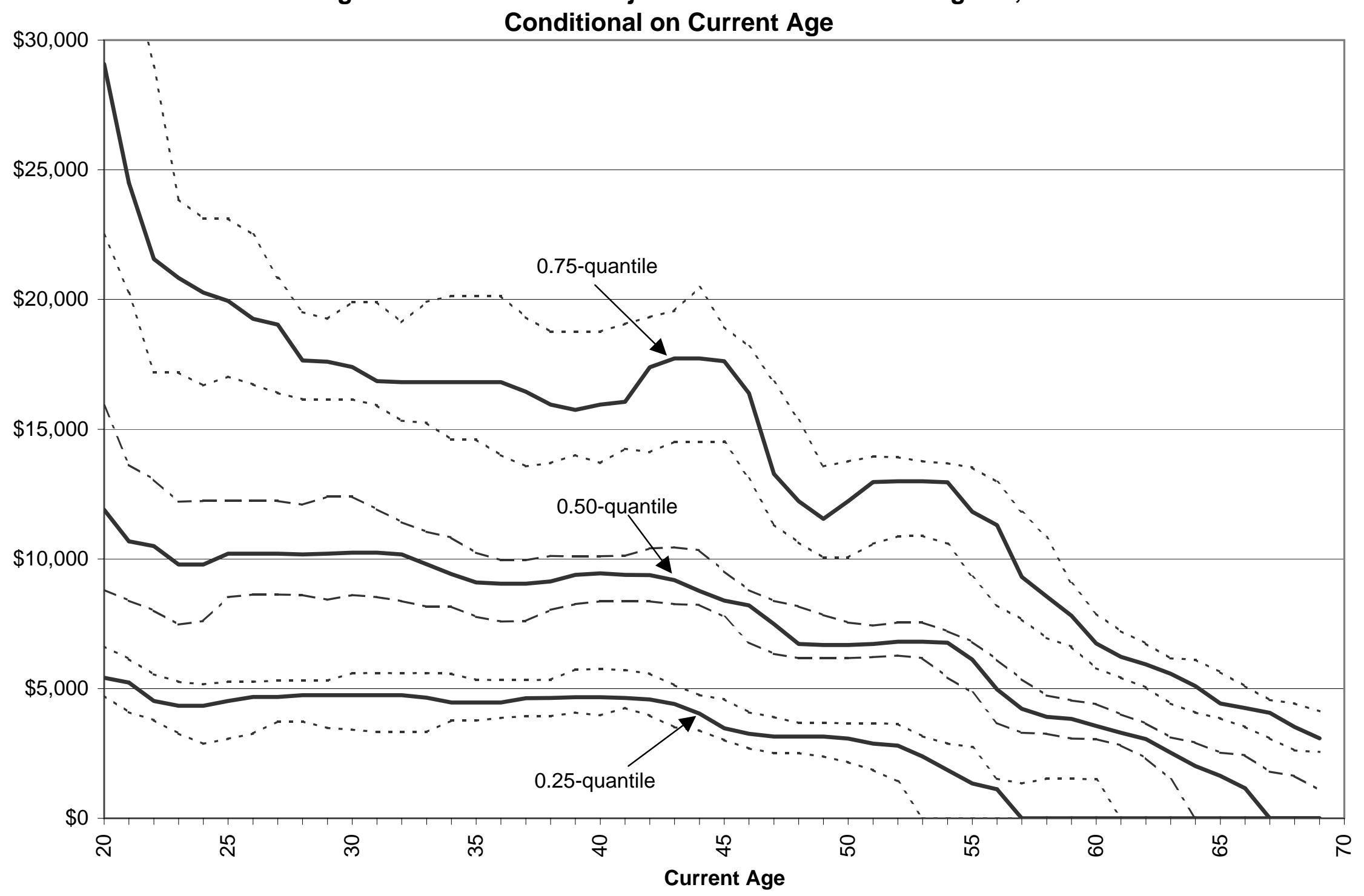

Conditional quantiles estimated using gaussian kernel with bandwidth of two years (1398 observations). Solid curves depict point estimates. Dashed curves depict bootstrap $90 \%$ confidence intervals. 
Figure 7. Quantiles of Subjective Median of Benefits at Age 70, Conditional on Probability of Eligibility

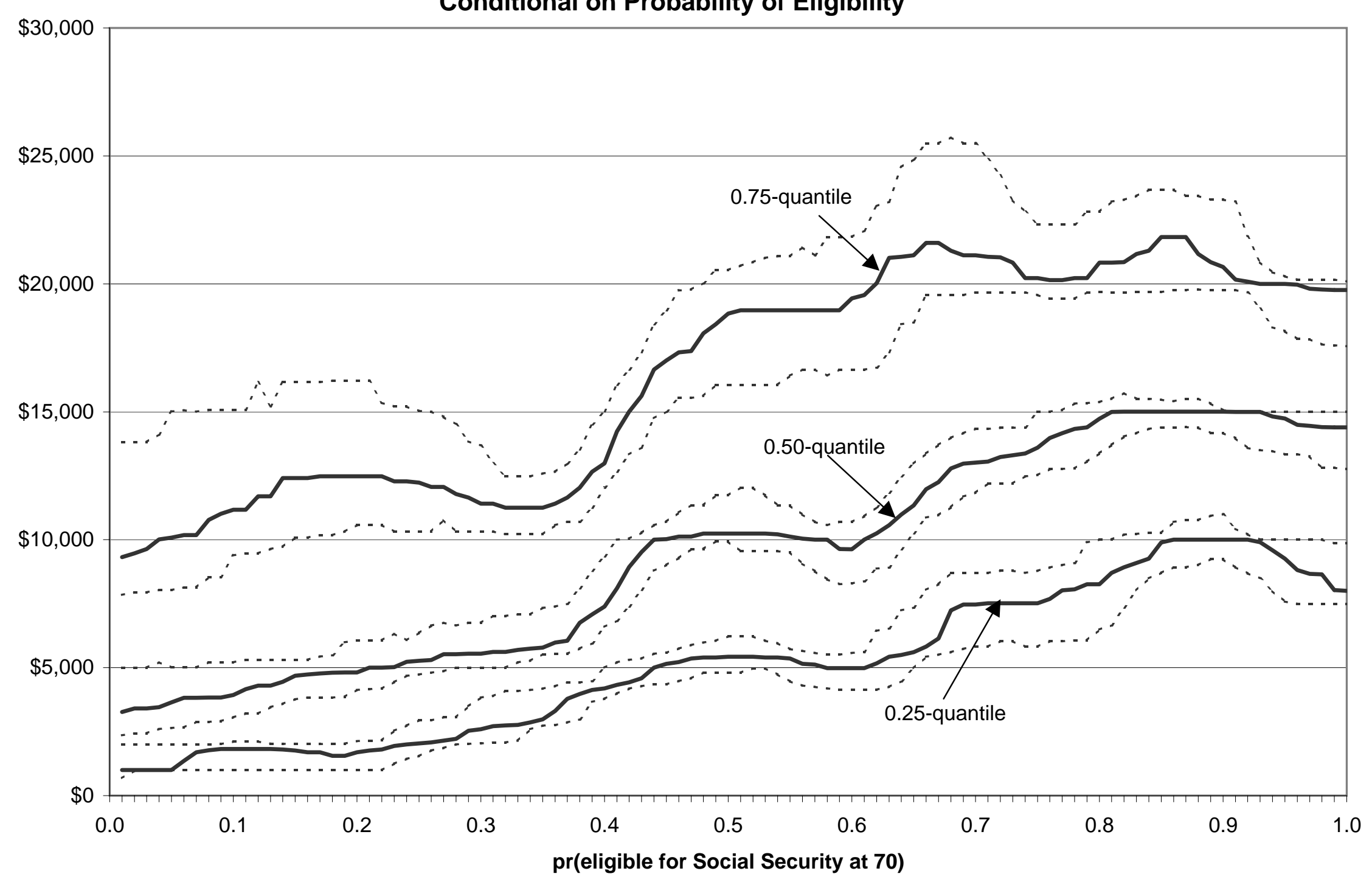

Conditional quantiles estimated using gaussian kernel with bandwidth of five percentage points (1398 observations). Solid curves depict point estimates. Dashed curves depict bootstrap 90\% confidence intervals. 
Figure 8. Quantiles of Subjective IQR of Benefits at Age 70, Conditional on Probability of Eligibility

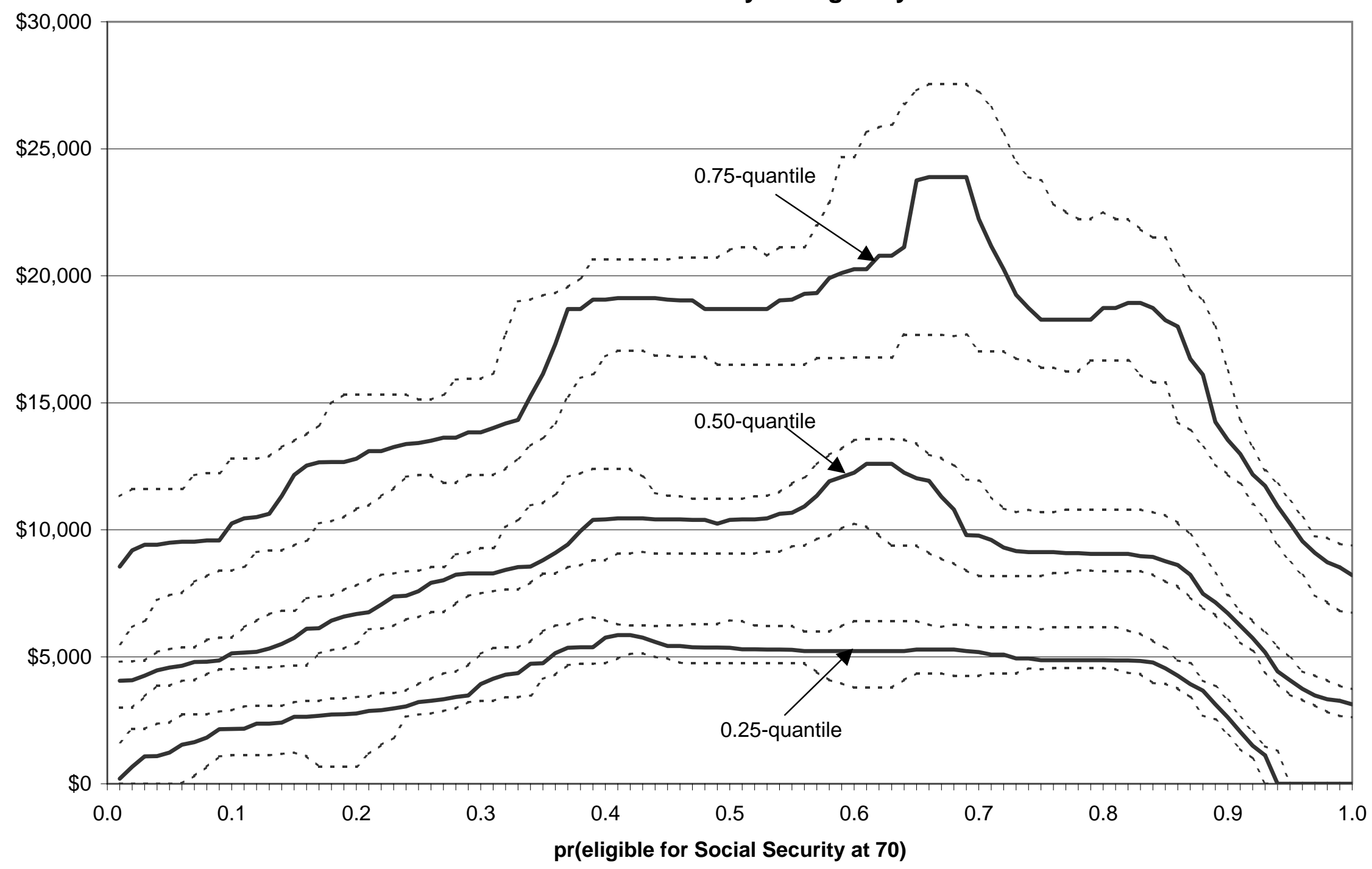

Conditional quantiles estimated using gaussian kernel with bandwidth of five percentage points (1398 observations). Solid curves depict point estimates. Dashed curves depict bootstrap 90\% confidence intervals. 
Figure 9 Quantiles of Unconditional Subjective Median of Benefits at Age 70, Conditional on Current Age

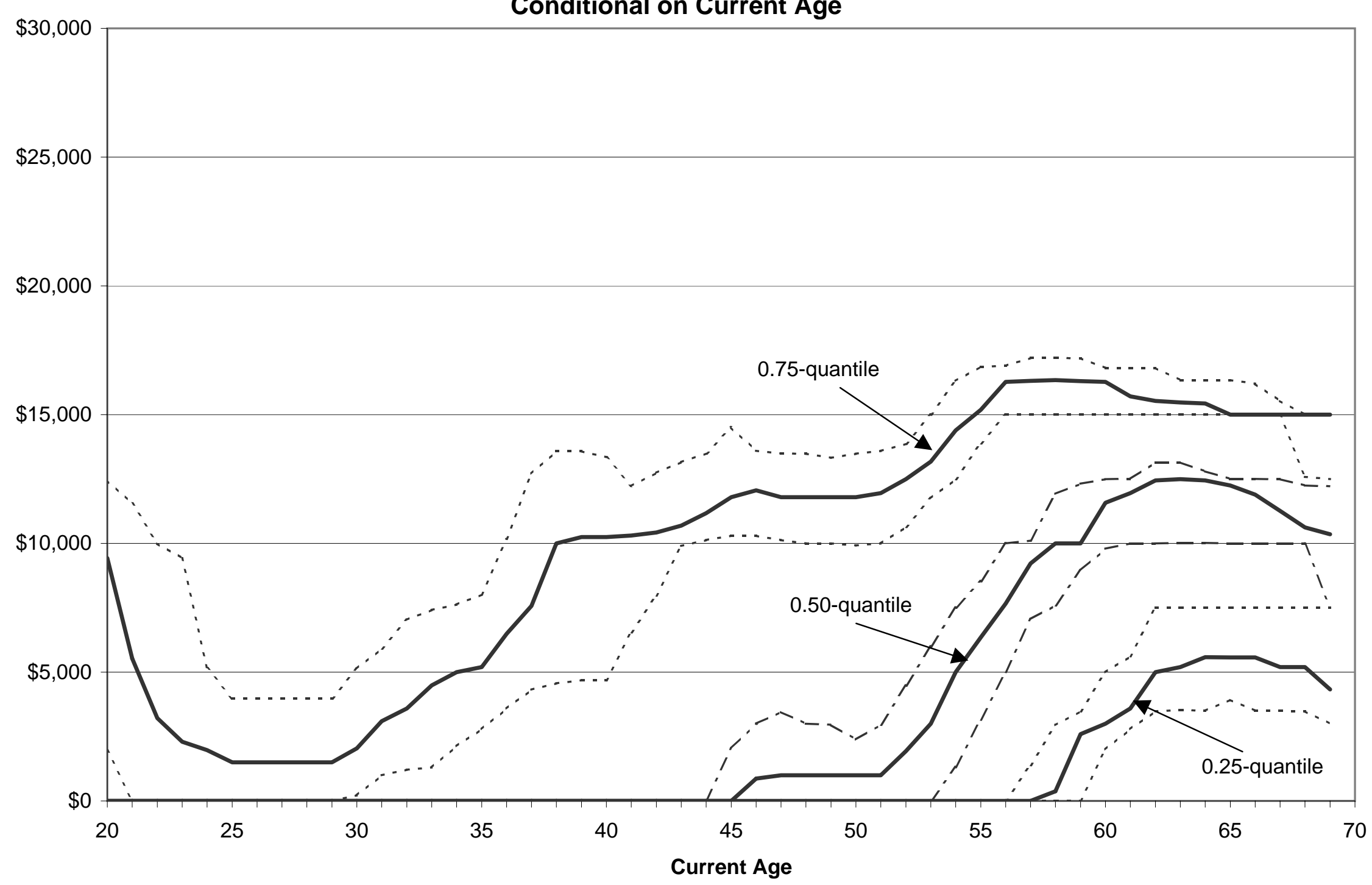

Conditional quantiles estimated using gaussian kernel with bandwidth of two years (1398 observations). Solid curves depict point estimates. Dashed curves depict bootstrap $90 \%$ confidence intervals. 
Figure 10. Expectations of Current Benefits: Subjective Median and "Best Estimate"

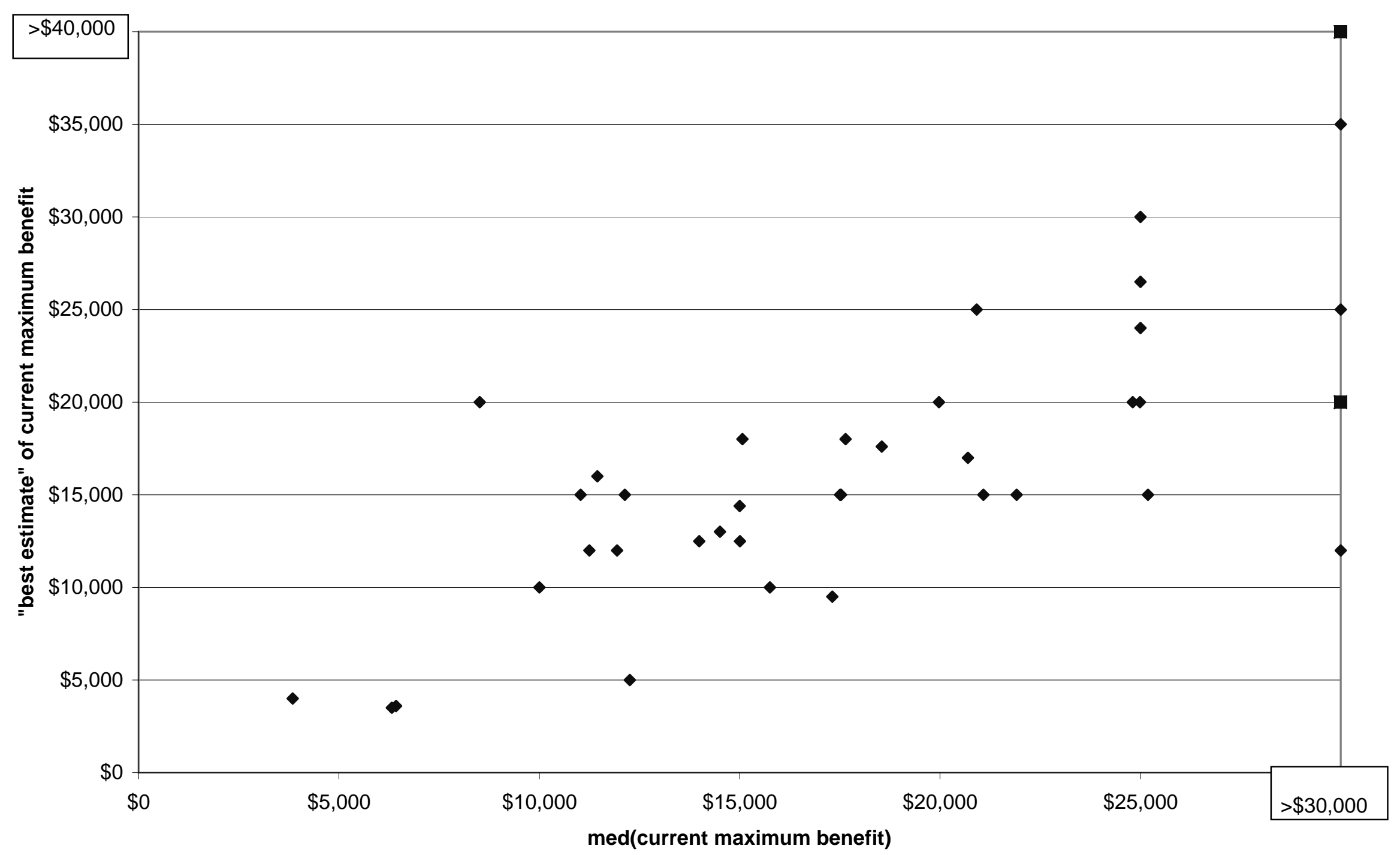


Figure 11. Expectations of Current Benefits: Subjective Median and Subjective IQR

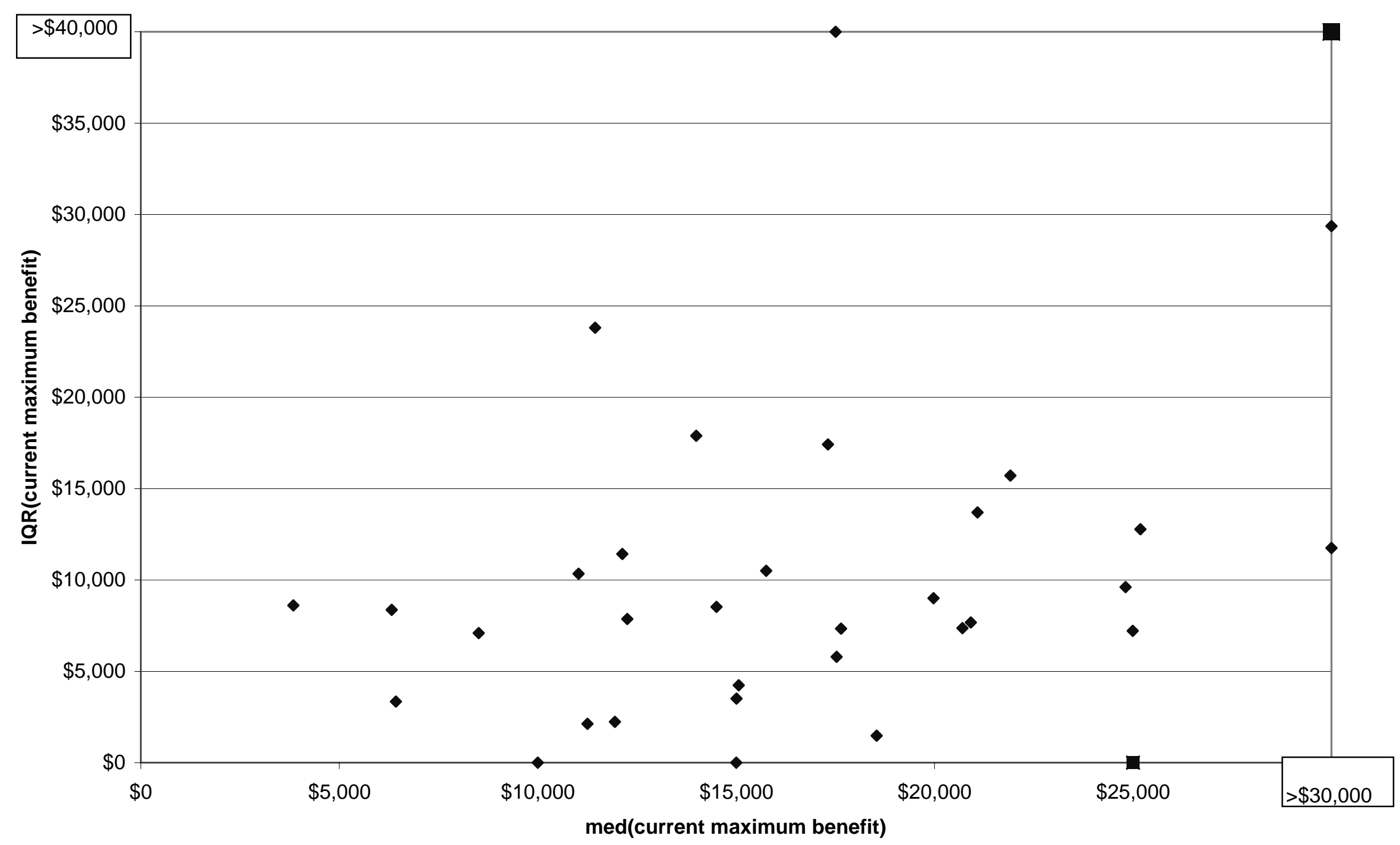


Figure 12. Expectations of Current and Prospective Benefits: Subjective Medians

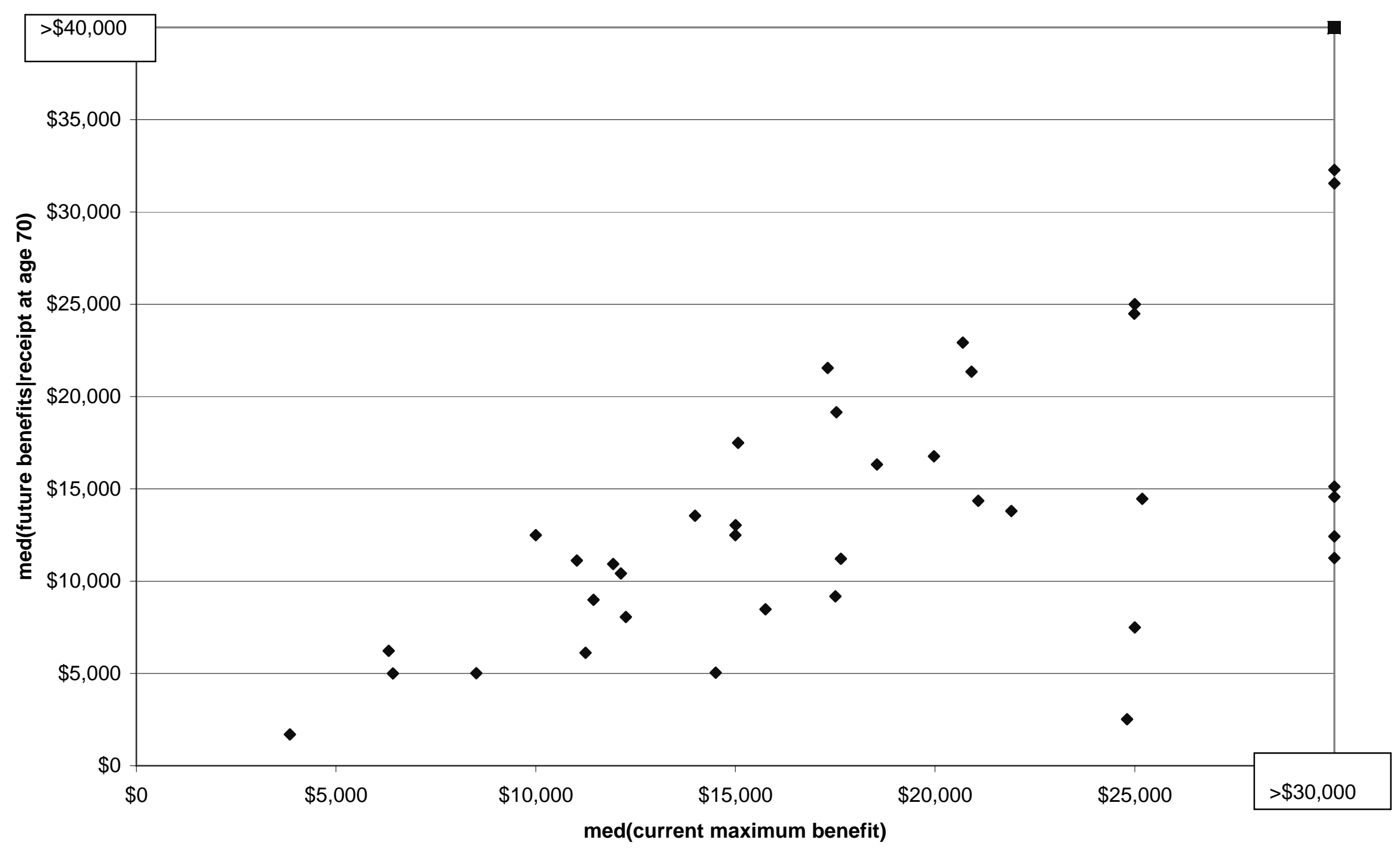


Figure 13. Expectations of Current and Prospective Benefits: Subjective IQRs

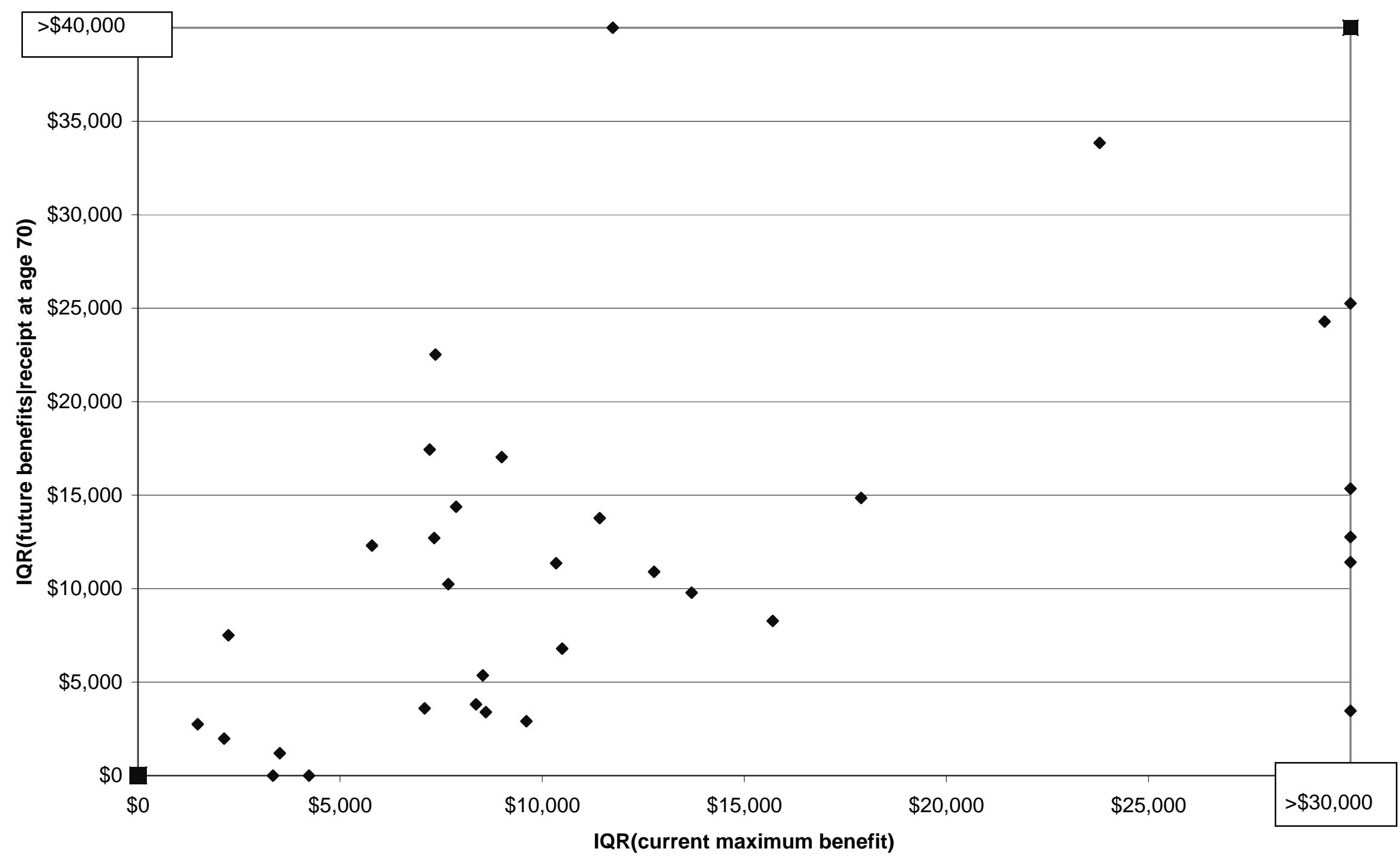




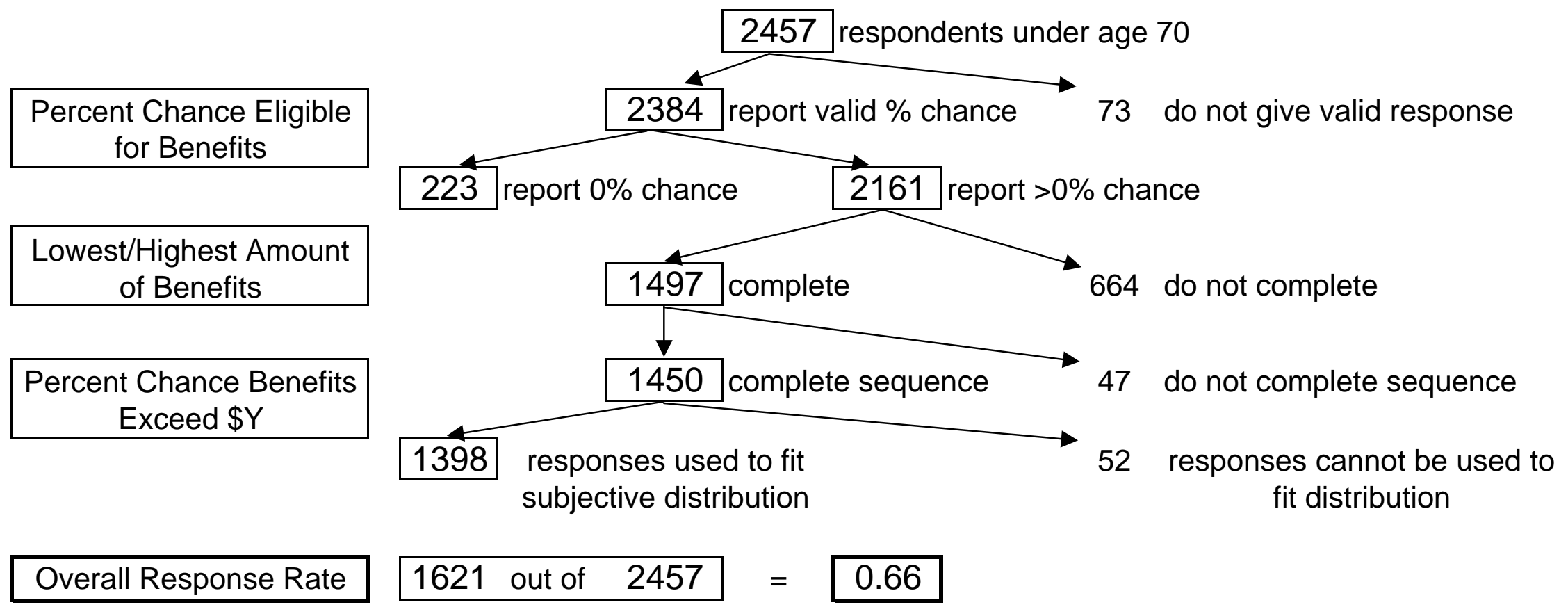

\section{Response Rate to HRS (2000) Questions}

\begin{tabular}{|c|}
\hline $\begin{array}{l}\text { Expect to Receive } \\
\text { Benefits }\end{array}$ \\
\hline $\begin{array}{c}\text { Expected Age When } \\
\text { Start Collecting Benefits }\end{array}$ \\
\hline $\begin{array}{l}\text { Expected Amount of } \\
\text { Benefit Payments }\end{array}$ \\
\hline
\end{tabular}

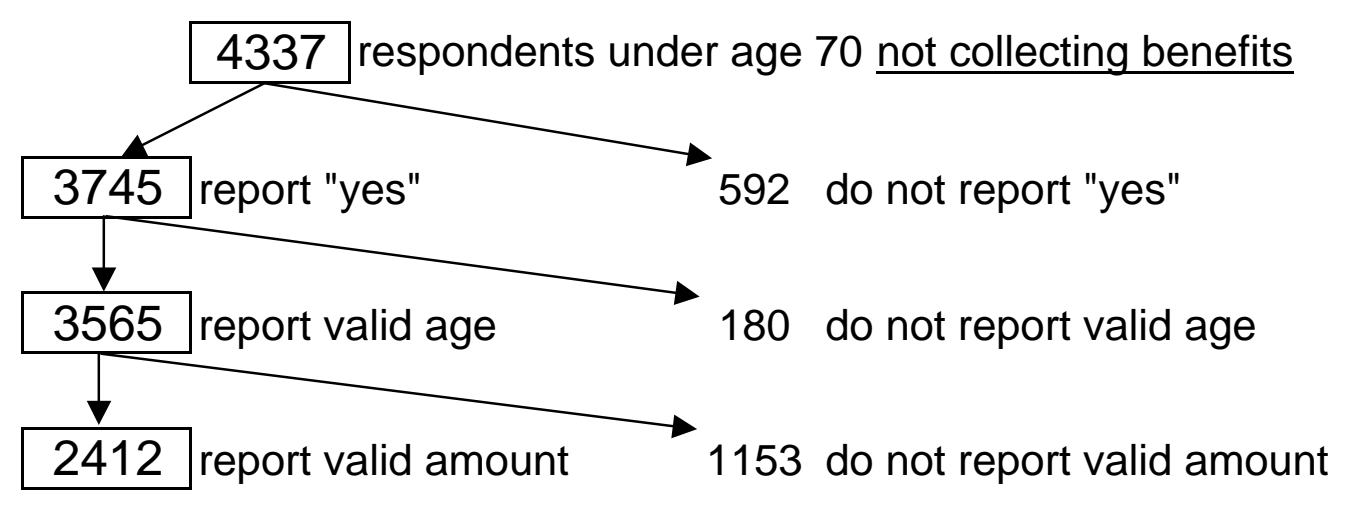

Overall Response Rate

2412 out of $4337=0.56$

